\title{
EL EMPRENDIMIENTO ¿ACTITUD O COMO COMPETENCIA DEL CAPITAL HUMANO? UNA MIRADA CONCEPTUAL DESDE LA UNIVERSIDAD DE HOLGUÍN, CUBA
}

\author{
A. L. T. BLÁZQUEZ ${ }^{1,}{ }^{*}$, C. R. V. ZALDÍVAR ${ }^{2}$, E. F. LEITE $^{3}$ \\ ${ }^{1,2}$ Universidad de Holguín, Cuba, ${ }^{3}$ Universidad de Pernambuco, Brasil \\ anatbcuba@gmail.com ${ }^{*}$
}

Submetido 14/08/2017 - Aceito 22/12/2018

DOI: 10.15628/holos.2018.7954

\begin{abstract}
RESUMEN
El emprendimiento a nivel internacional, es estudiado como un fenómeno económico resultante de la necesidad financiera que nace de la espontaneidad del individuo. Cuba con su nuevo modelo económico aspira a un desarrollo económico y social que logre satisfacer integralmente las necesidades espirituales y materiales del ser humano. Este contexto demanda personas innovadoras, capaces de convertir sus necesidades en oportunidades para empreender tanto en el entorno empresarial ya establecido, como en nuevos negocios particulares que surgan para dar respuesta a las demandas cada vez mas crecientes de la sociedad. Los diferentes enfoques teóricos y metodológicos acerca del emprendimiento como fenómeno, permitieron identificar las características y dimensiones que lo conforman como fenómeno social de gran trascendencia en la actualidad. La integración de estas dimensiones, materializadas en el desempeño laboral superior de un individuo, al ejecutar una actividad laboral determinada,
\end{abstract}

permitieron definirlo como una competencia del capital humano, que vas mas allá de una actitud. En la investigación se contextualizan estas características y dimensiones al entorno cubano, para contar con organizaciones emprendedoras que contribuyan al desarrollo socioeconómico del país. Se manifiesta la necesidad del desarrollo del emprendimiento como competencia del capital humano, como la fuerza interior que permite a las personas dado un entorno fijarse nuevas metas y ser capaces de construirlas, tener iniciativa, afrontar con fortaleza los problemas y resolverlos de manera creativa, sortear las dificultades y aprovechar las oportunidades con un alto sentido ético y de responsabilidad social.La novedad científica del estudio radica en la posibilidad de desarrollar la concepción del emprendimiento como una competencia del capital humano, cuya sistematización contribuye al desarrollo de una cultura emprendedora en cualquier organización.

PALAVRAS-CHAVE: Emprendimiento, dimensiones, características, competencia del capital humano.

\section{THE ENTREPREUNERSHIP, ATTITUDE OR LIKE COMPETITION OF THE HUMAN CAPITAL? A CONCEPTUAL LOOK FROM HOLGUÍN'S UNIVERSITY, CUBA}

\begin{abstract}
The entrepreunership to international level, it is studied like a cost-reducing resulting phenomenon of the financial need that grows from the individual's spontaneity. Cuba with his new cost-reducing model aspires to a cost-reducing and social development that you manage to fulfill the spiritual needs and the human being's materials wholly. This context sues innovative, capable people to turn its needs into opportunities for empreender so much at the entrepreneurial surroundings right now established, like in new particular business than surgan to give answer to the more and more increasing requests of the society. The different theoretic focuses and metodológicos about the emprendimiento like phenomenon, they allowed identifying characteristics and dimensions that conform it like social phenomenon of great transcendence as of the present moment. The integration of these dimensions, materialized in the labor superior performance of an individual to execute a labor determined activity, they allowed defining it
\end{abstract}

as a competition of the human capital, that you surpass an attitude. In investigation himself contextualizan these characteristics and dimensions to the surroundings Cuban, in order to count on enterprising organizations that they contribute to the socioeconomic development of the country. The need of the development of the emprendimiento like competition of the human capital, like the interior force that allows the people once a surroundings was given proves to new goals and being able to construct them, having initiative, facing with fortress problems pay attention and to make up your mind of creative way, to sort difficulties and to make good use of the opportunities with a height felt ethical of responsibility and social.La scientific new thing of the study consists in the possibility to develop the conception of the emprendimiento like a competition of the human capital, whose systematization contributes the development of an enterprising culture in any organization.

KEYWORDS: Entrepreuneship, dimensions, characteristics, competition of the human capital. 


\section{INTRODUCCIÓN}

El emprendimiento, fenómeno que en el mundo lleva muchos años de experiencia, en Cuba comienza a desarrollarse en estos últimos años, con el objetivo de mejorar el bienestar y lograr una economía adaptada a las nuevas condiciones internas y externas, donde sea posible el desarrollo sostenible y una mejor calidad de vida.

El estímulo a la creación de entidades de pequeña y mediana dimensión, lo que mundialmente se conoce como PYMES (pequeñas y medianas empresas), si se estructura adecuadamente con otros objetivos estratégicos puede hacer una contribución importante en tres de las dimensiones más importantes del desarrollo, como son el progreso de los territorios, la creación de empleo productivo y la mejoría del ingreso. A esto se suma que sirve para formalizar una parte no despreciable de la actividad económica que transcurría en el mercado negro, con lo que mejoran los ingresos al Presupuesto del Estado.

Aunque en el lenguaje corriente el término emprendimiento se asocia al hecho de dar inicio a una unidad económica, en realidad este término tiene un significado más amplio. El emprendimiento es una actitud propia de cada persona que le da la capacidad y la motivación para emprender nuevos proyectos que le permitan generar beneficios, tanto personales como sociales. Esta actitud se convierte en un motor que permite avanzar, con mucha perseverancia y sacrificio personal, hacia el cumplimiento de las metas y hacia terrenos de innovación alcanzando mayores logros. Es una forma de pensar, razonar y actuar centrada en las oportunidades, planteada con visión global y llevada a cabo mediante un liderazgo equilibrado y la gestión de un riesgo calculado, su resultado es la creación de valor que beneficia a la empresa, la economía y la sociedad.

En un análisis exploratorio inicial aplicado tanto en la Universidad de Holguín como a diversos trabajadores por cuenta propia (sector no estatal) del territorio holguinero, muestran el desconocimiento del término emprendimiento (91\% de los encuestados), y solo asocian el crecimiento del sector no estatal, a la necesidad financiera que nace de la espontaneidad del individuo, sin la aplicación de herramientas, métodos y técnicas que orienten su desarrollo, que tenga en cuenta los rasgos y particularidades de este sector, que posibiliten la estabilidad y madurez del negocio, y garanticen el aporte al desarrollo social que el territorio holguinero necesita. En el trabajo se muestra un estudio teórico acerca del emprendimiento y las competencias del capital humano, para luego aplicar algunas herramientas en el sector estatal y no estatal del municipio de Holguín, Cuba, que posibilitó determinar las dimensiones y características propias del emprendimiento para llegar a definirlo como competencia del capital humano.

\section{REVISIÓN BIBLIOGRÁFICA}

\subsection{El emprendimiento como competencia del capital humano}

El emprendimiento como fenómeno, ha cobrado importancia a nivel global. La tendencia internacional es valorarlo como un proceso económico que con el tiempo se transforma en una empresa o negocio que obtiene beneficios sin los cuales la empresa pierde su capacidad de crecer y desarrollarse (Padilla Martínez, Quispe Otacoma, Nogueira Rivera, Hernández Nariño, y Moreno Gavilanez, 2018). Por otra parte, diversos estudios centran su atención en la conceptualización del emprendimiento como una característica que puede surgir en todos los 
seres humanos (Jaramillo, 2008) y que tributa a la obtención de mejores resultados en su desempeño.

A su vez, en la gestión del capital humano en una organización, percibir las competencias laborales como la representación del nexo de las conductas o desempeños individuales con la estrategia de la organización (Hamel y Prahalad, 1994) permite que su gestión implique una mayor integración entre estrategia, sistema de trabajo y cultura organizacional. Todo esto, ligado a un conocimiento mayor de las potencialidades de las personas y su formación (Marrero Fornaris, 2002; Álvarez Santos y Anglés Peña, 2012; Marrero y Moré, 2017). El emprendedor utiliza sus competencias laborales para responder a las necesidades de un mercado cada vez más segmentado (Leite y Gouveia, 2000). En tal sentido, los autores de la investigación consideran oportuno profundizar en el enfoque de competencias en la gestión del capital humano y en el emprendimiento como competencia a desarrollar para el logro de las metas organizacionales.

\subsubsection{El enfoque de competencias en la gestión del capital humano}

En toda organización el factor humano es un elemento fundamental, que tendrá como apoyo los recursos materiales y financieros, pero en todos los casos es el ser humano quien marca la ruta a seguir y los resultados a alcanzar (Marrero Fornaris, 2002; Cuesta Santos, 2008; Leyva del Toro, 2016). El tratamiento del factor humano en las organizaciones ha evolucionado desde el restringido enfoque de administración de personal, seguido por el de recursos humanos hasta llegar al actual de capital humano (Cuesta Santos y Valencia Rodríguez, 2018).

Para esta investigación se empleará el término capital humano que es el más apropiado para las condiciones de una organización productiva y de servicios en Cuba, encargada de hacer emerger el valor que se encuentra en los recursos humanos que posee y cuya gestión debe culminar con la obtención de resultados económicos. Como expresa Cuesta Santos et al. (2018), "el concepto de capital humano asumido es derivado del pensamiento de Fidel Castro, pudiéndose constatar en la actualidad que Cuba tiene en su capital humano "la fuente principal de los recursos y del desarrollo". Como expresara Fidel $^{1}$ y planteara ya desde 1960, "El futuro de nuestra Patria tiene que ser, necesariamente, un futuro de hombres de ciencia, de hombres de pensamiento" ${ }^{2}$. El concepto de capital humano asumido de ese pensamiento, comprende economía, ciencia y conciencia ética (valores).

Según Cuesta Santos (2011), las personas constituyen el factor estratégico para el cumplimiento de las metas de cada uno de los procesos de la organización y, por tanto, se considera la gestión del capital humano como clave para la consecución de los objetivos estratégicos. Por otra parte, la orientación de las proyecciones de la entidad hacia el largo plazo debe incluir la planificación del personal en cantidad y calidad, y la relación entre la gestión del capital humano y los procesos estratégicos. El desarrollo del capital humano en las entidades de producción y servicios con un enfoque de competencia es un aspecto de extraordinaria importancia para el logro del incremento sostenido de la productividad del trabajo y la satisfacción laboral. Las competencias permiten establecer políticas y sistemas de gestión de personas orientados a potenciar los comportamientos de éxito para conseguir los resultados esperados.

\footnotetext{
${ }^{1}$ Castro F. Discurso pronunciado en la primera graduación de la Escuela Latinoamericana de Medicina, el 20 de agosto de 2005.

2 Castro F. Discurso pronunciado en el acto celebrado por la Sociedad Espeleológica de Cuba en la Academia de Ciencias, el 15 de enero de 1960. [Citado: 28 de febrero del 2018]. Disponible en: www.cuba.cu/gobierno/discursos/1960/esp/f150160e.html
} 
La gestión por competencias laborales se enfoca esencialmente en el desarrollo y en lo que las personas "serán capaces de hacer" en el futuro. A esa gestión, el pensamiento estratégico y la proactividad le son inherentes. Este enfoque es una concepción que implica mayor integración entre estrategia, sistema de trabajo y cultura organizacional, junto a un conocimiento mayor de las potencialidades de las personas y su desarrollo (Cuesta Santos, 2011). El estudio de varias definiciones que aparecen en la literatura (Boyatzis, 1982; Levy Leboyer y Prieto, 1997; Cowling, Newman, y Leigh, 1999; Zayas Agüero, 2002; Alles, 2006; Cuesta Santos, 2010; Lingling, Xuhui, Cunrui, y Fei, 2014; Duque Ceballos, García Solarte, y Hurtado Ayala, 2017) permitió identificar las variables comunes de interés para el estudio, tales como: habilidad, comportamiento, rendimiento, conducta, capacidades, conocimientos, experiencias adquiridas, atributo personal, valores y motivos. Se construyó una matriz binaria a partir de la presencia o no de las variables. A partir del Statistic Program for Social Sciences (SPSS) se realizó un análisis de conglomerados jerárquico por autores. Se utilizó el método Ward distancia euclidiana al cuadrado y su validación se realizó a través de la comparación de sus resultados (figura 1.1) con los análisis de redes sociales Ucinet for Windows: Software for Social Network Analysis, al utilizar el indicador de centralidad.
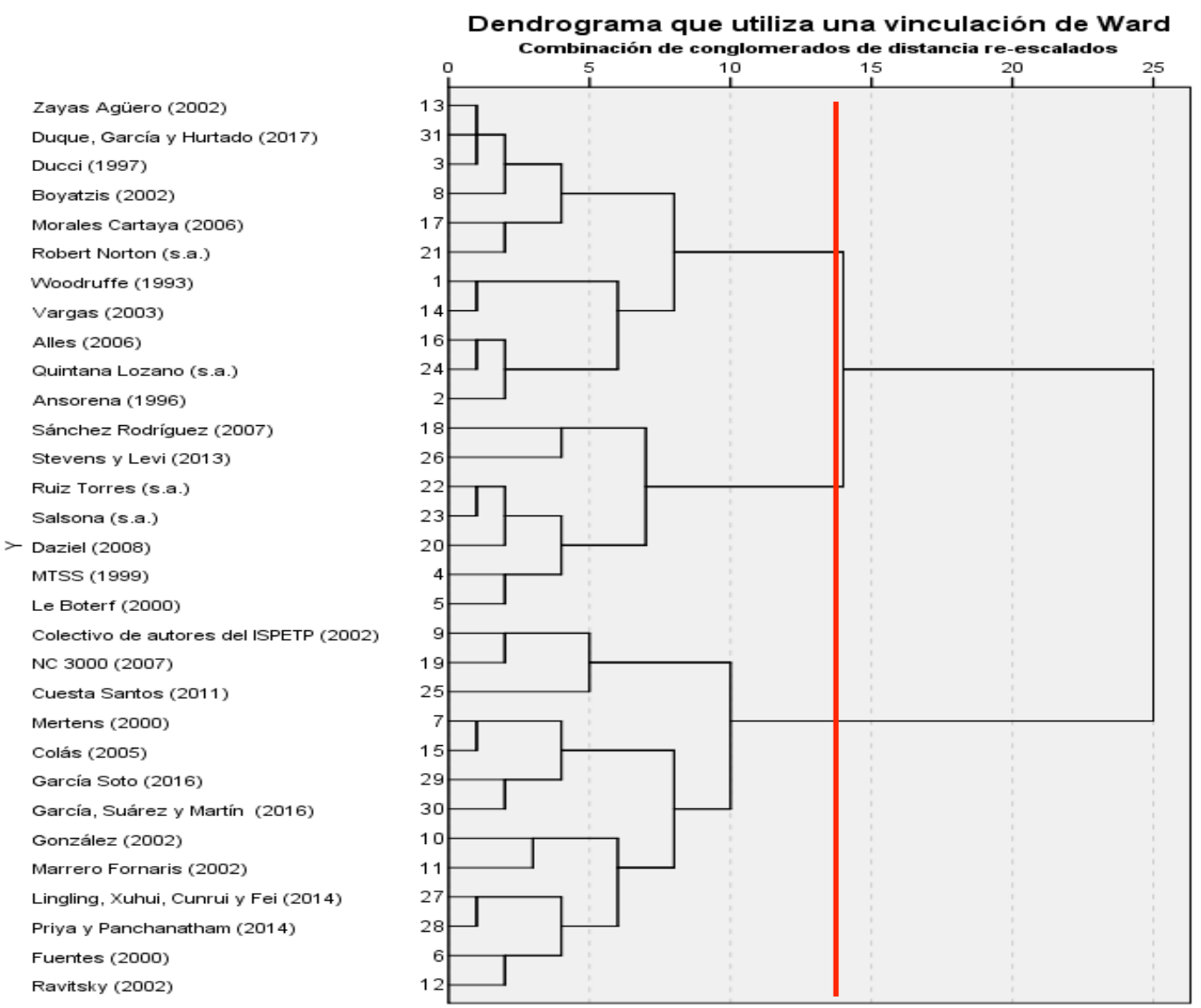

Figura 1.1: Dendograma resultante del análisis de las definiciones de competencias laborales.

Como resultado del análisis se determinó hacer el corte a la distancia de diez y se identificaron cuatro grupos de autores: un primer grupo que asocia el concepto de competencia a rendimiento, habilidad y comportamiento; un segundo grupo que lo vincula a la conducta, habilidad, atributo personal, aptitud, conocimientos y experiencias; un tercer grupo que lo relaciona con rendimiento, habilidad, comportamiento, aptitud, conocimientos, valores, 
experiencias adquiridas, capacidades y motivos; y un cuarto grupo que lo visualiza como habilidad, conocimiento, capacidades, comportamiento y motivos. A los efectos de esta investigación, los autores se suman al tercer grupo pues es en éste donde ella considera que se alude al comportamiento ético de las personas.

En la figura 1.2 se muestra la correlación que existe entre los autores estudiados y los conceptos asociados en las definiciones de competencias laborales donde se muestran la habilidad, el comportamiento y el rendimiento como los de mayor correlación entre los autores estudiados seguido de conductas, capacidades, conocimientos, experiencias adquiridas, atributo personal, aptitud y valores.

A partir del análisis realizado, los autores coinciden con el enfoque que aparece en los trabajos de Morales Cartaya (2006) que considera como competencias laborales el conjunto sinérgico de conocimientos, habilidades, experiencias, sentimientos, actitudes, motivaciones, características personales y valores basado en la idoneidad demostrada y asociado a un desempeño superior del trabajador y de la organización en correspondencia con las exigencias técnicas, productivas y de servicios.

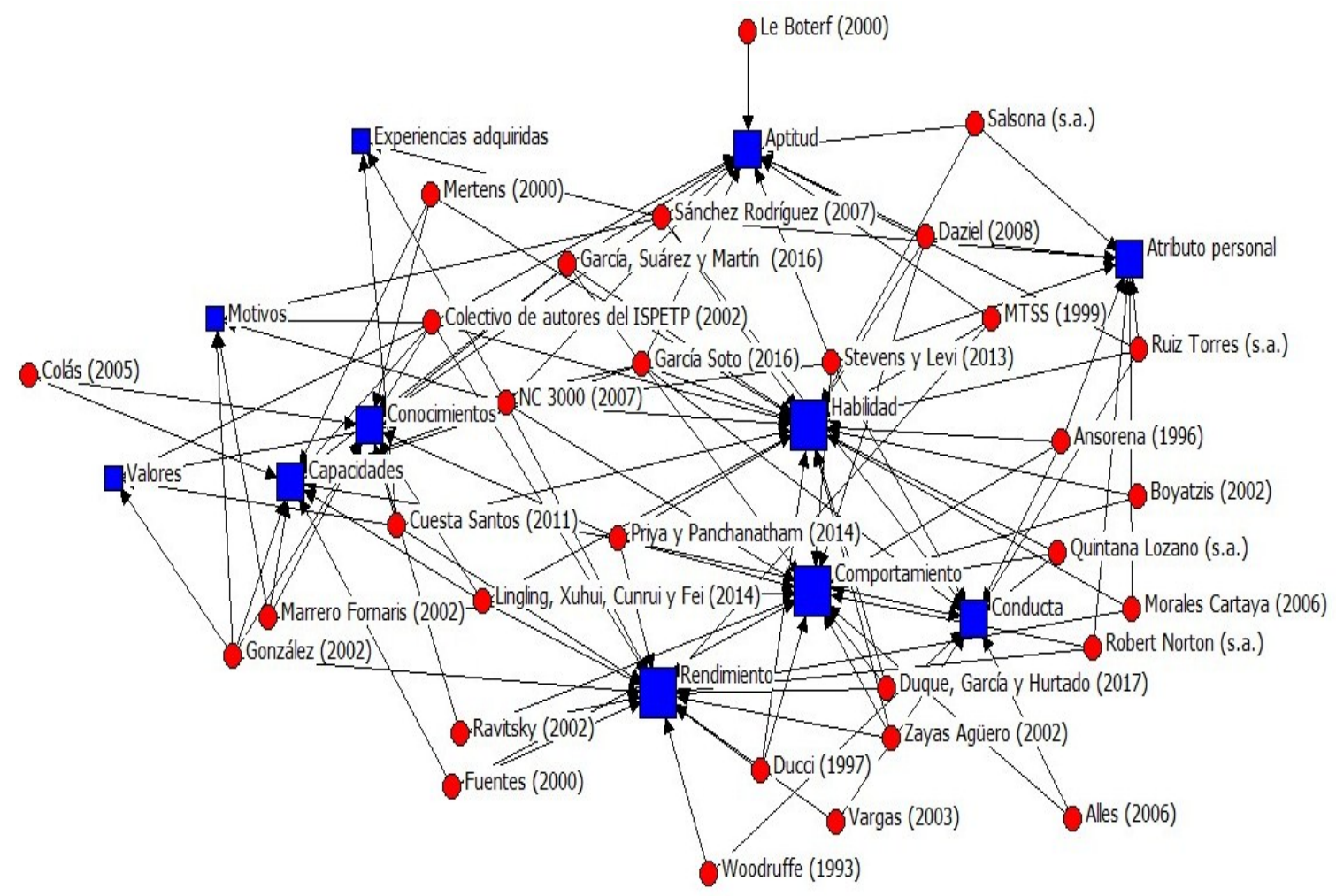

Figura 1.2: Red de relaciones entre autores con respecto a las definiciones de competencias laborales.

Se puede afirmar que la gestión por competencia es esencial en la moderna gestión del capital humano $(\mathrm{GCH})$ en general y en varios de sus procesos claves (Cuesta Santos, 2001). A partir de los elementos expuestos los autores consideran que, dentro de las tendencias de la gestión del capital humano, la gestión por competencias laborales permite a la organización disponer del capital humano que le posibilite cumplir su misión y visión con resultados satisfactorios y así escalar a estadios superiores de desarrollo para ser más competitivos y con mayor sostenibilidad en el rendimiento de sus procesos, productos y servicios. 


\subsubsection{El emprendimiento. Antecedentes y conceptos fundamentales}

El emprendimiento es un término muy utilizado en la actualidad, aunque ha estado presente a lo largo de la historia de la humanidad pues es inherente a esta. En las últimas décadas, este concepto ha cobrado gran importancia ante la necesidad de superar los constantes y crecientes problemas económicos (Stevenson del Vecchio y Velázquez Zaldívar, 2007). El concepto de emprendimiento se origina del francés entrepreneur que significa pionero, frente a la aventura y a la incertidumbre. Se define como innovador, líder y creativo ante situaciones del entorno (Castillo, 1999; Uslu, 2015; Camelo-Ordaz, Diánez-González, y Ruiz-Navarro, 2016).

El emprendimiento no es neutral, depende del contexto histórico y está condicionado por el modo de innovación dominante que refleja una forma ser, sentir, pensar, hacer y hablar y que emerge del modo de innovación que es su fuente de inspiración y orientación (Lucas de Souza, 2005; Nová, 2015; Harpa, Moca, y Rus, 2016). El uso más habitual del concepto aparece en el ámbito de la economía y los negocios. En este caso, el emprendimiento es una iniciativa de un individuo que asume un riesgo económico o que invierte recursos con el objetivo de aprovechar una oportunidad que brinda el mercado (Valcarce y Sequera, 2005; Maryunani y Mirzanti, 2015; Miranda, Chamorro Mera, y Rubio, 2017). Sin embargo, en realidad este término tiene un significado más amplio.

Muchos son los enfoques y las formas de estudiar el fenómeno o la manifestación del emprendimiento (Zimmerer y Scarborough, 1996; Alvarez, Losada, y Comesaña, 2014; Yurtkoru, Kuşcu, y Doğanay, 2014; P. O. García y Capitán, 2016; Yıldırım, Çakır, y Aşkun, 2016; Pérez Díaz Pericles, 2017), no sólo a través del estudio del surgimiento de nuevas empresas, sino también, por el análisis de la toma de decisiones y realización emprendedora en un determinado momento o situación. Algunos de los investigadores buscan explicaciones en las características especiales y diferenciadas de los emprendedores; otros las atribuyen a sus respuestas en las distintas circunstancias, cambios y presiones ofrecidas por el entorno o ambiente en el cual están inmersos; y otros en la unión de ambos, los aspectos personales y del entorno (Lucas Souza y Sueiro Lopez, 2011; Teixeira, Ducci, Sarrassini, Munhê, y Ducci, 2011; Gedik, Miman, y Kesici, 2015).

Todos estos esfuerzos y enfoques, individuales o conjuntos, contribuyen en la búsqueda de una mejor convergencia en la explicación, contextualización y conceptuación del emprendimiento; sin embargo, todavía no existe consenso ni teoría universalmente aceptada. Numerosas aportaciones teóricas han sido realizadas por investigadores a lo largo del tiempo, entre las que se destacan las siguientes:

Schumpeter (1984), concibe al emprendedor como aquel individuo con ideas innovadoras y con iniciativa de riesgo de transformación. Para este autor, el emprendedor no se mueve por lucro, vive de sus cambios los cuales no ve como amenazas sino como oportunidades de negocio. El emprendedor Schumpeteriano utiliza sus competencias laborales para responder a las necesidades de un mercado cada vez más segmentado (Leite et al., 2000). Este autor define "la fuerza destructiva creativa" como la característica central del emprendedor innovador que con sus habilidades realiza nuevas combinaciones de los recursos para utilizarlas en la ejecución de nuevas oportunidades económicas identificadas por él y que no existían anteriormente. Un emprendedor es soñador, creativo, independiente y proactivo, con una visión prospectiva de su negocio, que prefiere la toma de riesgos calculados y que huye de las situaciones extremas de alto riesgo o de extrema certeza (Bikse, Rivza, y Riemere, 2015). 
El enfoque de Morrison (1998) se centra en los rasgos innatos y las motivaciones. Para este autor, la capacidad de tomar riesgos y el deseo de crear negocios son rasgos innatos en el emprendedor que se proyectan en actitudes tales como: el estar alerta a las oportunidades, la creatividad, la toma de decisiones, el tener visión y otras (Díaz Barriga y Hernández Rojas, 2002). Desde esta perspectiva psicológica-social del emprendedor, McClelland (1973) y Leite et al. (2000) formulan postulados fundamentales en los que sostiene que las influencias sociales juegan un papel fundamental en el desarrollo de tendencias emprendedoras. Para estos autores todo individuo tiene motivos básicos o necesidades y a su vez estos representan potenciales de conducta e influyen sobre él únicamente cuando se les incita. El hecho de que estos motivos resulten incitados o no, depende de la situación o medio ambiente percibido por el individuo.

Drucker (1985), aplica el concepto de emprendedor a aquellas personas que están constantemente creando nuevos tipos de negocios y aplicando nuevos conceptos administrativos. Para este autor las autoridades, los universitarios, los alcaldes, entre otros, pueden actuar de forma emprendedora. El emprendedor como persona cuenta con una necesidad de logro, deseo de independencia y autorrealización. El principal motivo que les lleva a convertirse en emprendedores es crear su propio puesto de trabajo, poseen una gran ambición por el proyecto y confianza en sí mismos, demuestran mucha seguridad y se centran en la búsqueda de oportunidades a través de la innovación, no sólo en productos, sino en sistemas de producción, en nuevos mercados, en sistemas de marketing o venta, en canales de distribución, en métodos de organización, de dirección, en la forma de financiarse y a la hora de obtener la información y tecnología necesarias, es decir, innovación (Audretsch, 1999; Ribeiro Soriano, 2001; Kickul y Gundry, 2002; Butler, 2012; Draghici y Albulescu, 2014; Gámez Gutiérrez y Garzón Baquero, 2017). El emprendedor debe tener iniciativa (Smallbone y Welter, 2001; Valliere, 2015; Miranda et al., 2017) en las estrategias y cambios de la organización.

Otra mirada al emprendimiento se estructura desde el punto de vista psicológico y sociológico. El enfoque psicológico propone que las características personales que definen a los emprendedores son la necesidad de logro o éxito y la autorrealización (Veciana Vergés, 1996; Leite, 2006; Miranda et al., 2017); el control interno y autoconfianza en sus habilidades personales (Koellinger, Minniti, y Schade, 2007; Ferreira, Loiola, y Gondim, 2017); la propensión a asumir riesgos, como una función del nivel de riqueza - riqueza inversamente correlacionada con menor propensión a asumir riesgos (Jaramillo, 2008; Vereshchagina y Hopenhayn, 2009); y una situación de alerta respecto a las oportunidades en el mercado que materializa para crear o mejorar su empresa (Kirzner, 1997; Hnátek, 2015).

El enfoque sociológico enfatiza los factores externos al emprendedor como impulsores de la actividad emprendedora y la creación de empresas. Las personas con una amplia red de relaciones informales (familiares, amigos y vecinos) y formales (relaciones contractuales) son más propensas a crear empresas, aunque no necesariamente a innovar. Otro factor externo determinante para que las personas realicen emprendimientos productivos es el arreglo institucional, es decir, las instituciones forman la estructura de incentivos que, si resultan los adecuados, favorecen la función emprendedora (North, 1990; Sobel, 2008; Allali, 2010). Es posible definir a los emprendedores como "la persona que puede planificar y ejecutar estrategias para generar valor, que alinea sus expectativas personales y organizacionales, con una necesidad y oportunidad identificada en su entorno y con la capacidad de llevar eficaz y eficientemente su idea a la acción" (Ortiz y Mariño, 2003; Panc, 2015). Además, se sustenta que los empresarios se caracterizan por tener una combinación equilibrada de habilidades y experiencias en diferentes 
roles antes que ser especialistas en alguna área específica (Audretsch, 1999; Lisetchi y Brancu, 2014). También, varios estudios coinciden en que los emprendedores independientes tienen niveles de satisfacción personal más altos y son más felices (Blanchflower y Oswald, 1998; Salas, 2014; Momete, 2015) .

Según Fandiño y Bolívar (2008), el emprendimiento es una actitud propia de cada persona con la capacidad y la motivación para emprender nuevos proyectos que generen beneficios tanto personales como sociales. Esta actitud se convierte en un motor que permite avanzar, con mucha perseverancia y sacrificio personal, hacia el cumplimiento de las metas y hacia terrenos de innovación para alcanzar mayores logros. Una manera de pensar y actuar orientada hacia la creación de valor es una forma de pensar y actuar centrada en las oportunidades, planteada con visión global y llevada a cabo mediante un liderazgo equilibrado y la gestión de un riesgo calculado. Su resultado es la creación de valor que beneficia a la empresa, la economía y la sociedad.

Por otra parte, Julca Meza (2012); Zaman, Vasile, y Cristea (2012) y Zaman (2015) consideran que emprendimiento se refiere a la capacidad de una persona de realizar un esfuerzo adicional para alcanzar una meta; es también utilizada para la persona que inicia una nueva empresa o proyecto. Así mismo, este término se atribuyó a aquellas personas que fueron innovadoras o agregaban valor a un producto ya existente. Por tanto, la acepción que se tomó es la que se refiere a la aptitud y actitud de la persona que le permite emprender nuevos retos, nuevos proyectos, y avanzar más de lo esperado. Una persona emprendedora es capaz de aprovechar las situaciones de insatisfacción, los momentos de rutina, de poco crecimiento personal y laboral para desencadenar situaciones de satisfacciones y nuevos logros.

Como se observa existen diferentes enfoques para abordar el término emprendedor, unos tratan de describir y explicar qué es y otros qué hace. Desde esta perspectiva se puede señalar que en el emprendimiento influyen los rasgos individuales de la personalidad, la organización social que le rodea y en general, el medio económico en que se desenvuelve el emprendedor. Por lo que se puede señalar que, puede ser comprendido como un fenómeno en el que se conectan la dimensión individual y social de una persona, ya que coloca en perfecta correspondencia a la creación individual o colectiva con su entorno (marco de referencia para la acción), lo que significa además el surgimiento de iniciativas orientadas a la realización de actividades para un objetivo o beneficio que trascienda, en la mayoría de los casos, al interés y logro individual (Caldera, Rodríguez, y Moreno, 2013).

Los autores de la presente investigación se asocian a las definiciones de Leite (2006) y Julca Meza (2012), en las que el emprendedor se caracteriza por una actitud positiva, manifestada a través de la creación de un nuevo negocio o del auto empleo, por la toma de decisiones frente a oportunidades previamente identificadas por él o, por el comportamiento en la (re)organización y utilización eficaz de los recursos disponibles. Incluso, también se puede encontrar con la conjunción de todas ellas. Por tanto, el emprendimiento, ya sea visto desde un enfoque económico, psicológico, social - cultural o gerencial, se debe a las características personales, atributos y capacidades del emprendedor por lo que puede considerarse una competencia.

En la revisión bibliográfica realizada se encontraron criterios relacionados con el perfil del emprendedor que refuerzan su consideración como una competencia. El emprendedor posee 
rasgos netos de su personalidad que constituyen su perfil psicológico, el que lo impulsa a iniciar un proceso creador y transformador en el que asume riesgos. A este perfil se asocian ciertas conductas que pueden ser entrenadas y que tienen influencia en el resultado del emprendimiento.

Dentro de las aproximaciones más reconocidas para comprender el perfil del emprendedor se encuentra la realizada por Timmons, Spinelli, y Tan (1994), la cual a su vez es desarrollada por Morrison (1998). Para estos autores los factores dominantes del perfil emprendedor son: liderazgo, motivación por superarse, obsesión por la oportunidad, creatividad, confianza en sí mismo, tolerancia al riesgo, la ambigüedad y la incertidumbre, el compromiso y la adaptabilidad (G. García, 2002).

La Red Alfa Capacidad Emprendedora (Rusque, Ramírez, Torres, Guzmán, y Castillo, 1998) considera relevantes las siguientes variables para definir el perfil de un emprendedor: creatividad e innovación, capacidad para asumir riesgo, responsabilidad, altruismo, autoconfianza, honestidad, comunicación, liderazgo, coordinación y negociación. Por su parte, Ripsas (1998) ayuda a entender el perfil del emprendedor reuniendo algunas de sus características recogidas a lo largo de la literatura asociadas a la teoría económica: individuo que asume el riesgo asociado a la incertidumbre, que posee capital financiero, que es innovador, que toma decisiones, que es líder, directivo, organizador y coordinador de recursos económicos, propietario de empresa, empleador de factores de producción y árbitro.

Además de la necesidad de realización y la propensión al riesgo (McClelland y Winter, 1969) (McClelland, 1973) (Begley y Boyd, 1985; Van Praag y Cramer, 2001) (Stewart y Roth, 2007), otras características del emprendedor que hacen parte del conjunto de las más citadas por los investigadores del enfoque psicológico de la literatura son aquellas centradas en los valores personales del individuo tales como la honestidad, el deber, la responsabilidad y el comportamiento ético (Collins, Moore, y Unwalla, 1964; McClelland, 1973; Chye Koh, 1996; Cowling et al., 1999). El perfil del emprendedor propuesto por Leite et al. (2000) involucra alta necesidad de realización, elevados niveles de energía, el asumir riesgos, la autoconfianza, el saber resolver problemas, el desapego emocional, la necesidad de status y la necesidad de satisfacción personal.

Por otra parte, Parra Villanueva y Fleitas Triana (2010) expresan que el emprendedor es una persona con capacidad de crear, de llevar adelante sus ideas, de generar bienes y servicios, de asumir riesgos y de enfrentar problemas. Mientras que para Vainrub (2009) el emprendedor se caracteriza por un perfil que posee atributos como ser líder, vendedor de ideas, detallista, orientado a obtener resultados, activo, curioso, capaz de adaptarse a los cambios, transformador. La mayoría de los autores antes mencionados reconocen como las características para definir el perfil emprendedor: tener iniciativa, correr riesgos y tener liderazgo, autoconfianza, creatividad e innovación. Lo anterior quedó validado al confeccionar la red de relaciones entre las variables definidas por los mismos que se presenta en la figura 1.3. 


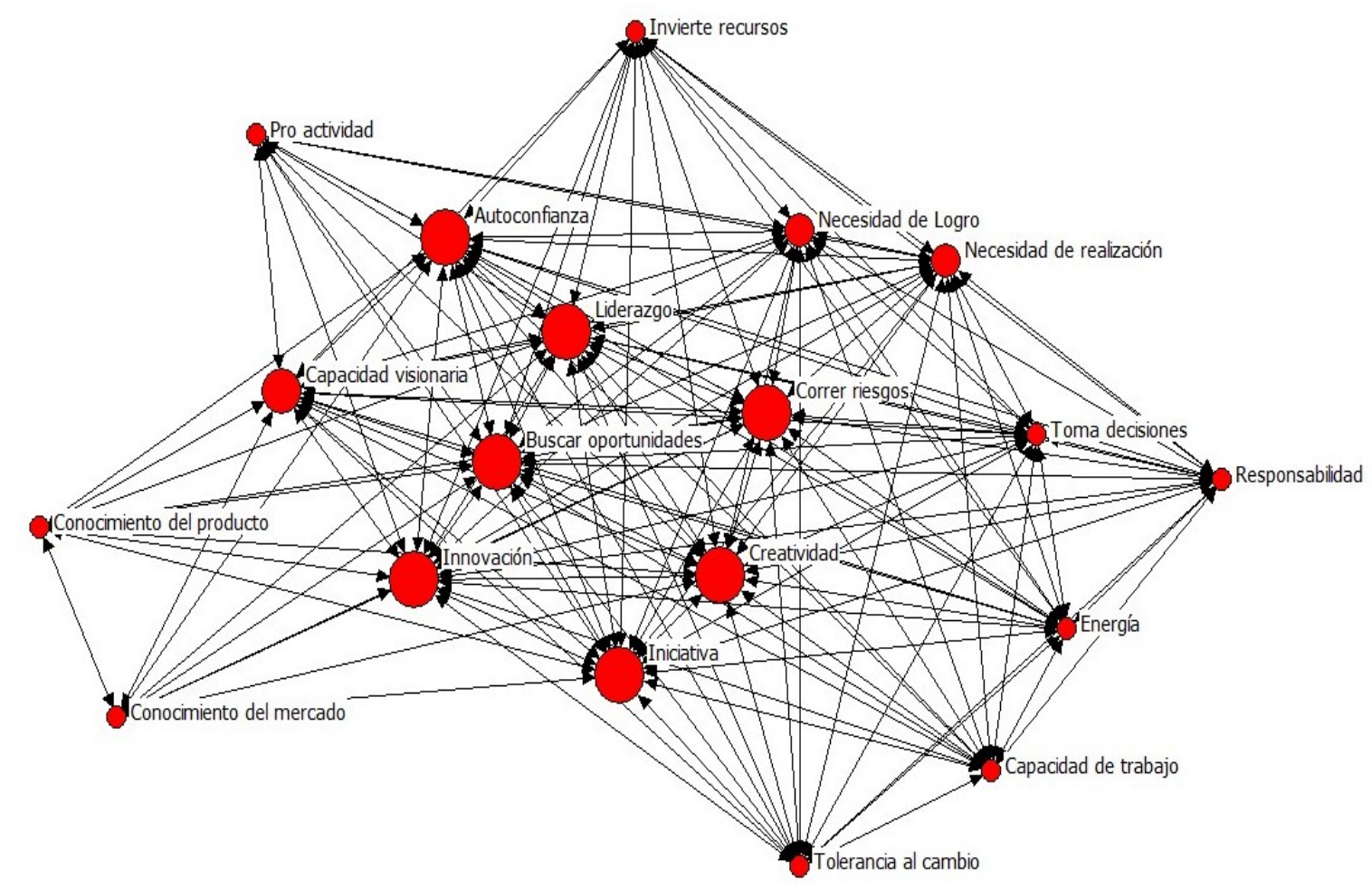

Figura 1.3: Red de relaciones entre las características del perfil emprendedor.

El desarrollo del espíritu emprendedor está centrado en el individuo, en estudiar sus dimensiones psicológicas, culturales y económicas, desde una perspectiva sistémica (Rodrigues de Siqueira, Peghini, Dias de Souza, y Bentode Oliveira Filho, 2014), criterio compartido por la autora de la investigación.

\subsection{La gestión del emprendimiento}

El Global Entrepreneurship Monitor (GEM), observatorio que a nivel internacional da seguimiento al emprendimiento como actividad que repercute en el desarrollo económico de los países. En su informe de 2016 expresa que toda sociedad que aspire a ser competitiva y gozar de mayores oportunidades debe contar con una sólida base emprendedora. Para ello, resulta significativo el impulso de procesos de gestión del emprendimiento, lo que requiere conocer con precisión las capacidades de las personas, su interés por aplicar las nuevas iniciativas empresariales o el potencial de las que ya están en marcha y el porcentaje de expectativas abandonadas. El GEM enfatiza en el componente económico (influencia del emprendimiento en el PIB de los países) y no como competencia del capital humano que es posible desarrollar.

La gestión del emprendimiento implica la combinación para iniciar cambios en la producción, los procesos o en los servicios. El emprendimiento es un fenómeno discontinuo que aparece para realizar cambios en el proceso y después desaparece hasta que aparece nuevamente para iniciar otro cambio (Wilken, 1979; Zaman, 2015). De modo que el administrador es el encargado de optimizar los recursos para sacar el mejor provecho de una situación o un conjunto de situaciones en particular, centrándose en las reglas existentes dentro de su entorno, limitándose a convivir con las mismas, respetándolas y acentuando su acción en bienes o servicios ya establecidos. Mientras el emprendedor visualiza una oportunidad, ya sea de una situación convulsa o de quietud en las condiciones y normas existentes dentro del mercado, rompe los esquemas y construye nuevas reglas. Su método de supervivencia se centra en gestionar el 
cambio. El fomento del emprendimiento aporta al menos tres beneficios para la sociedad: fomenta el crecimiento económico, aumenta la productividad y aporta nuevas tecnologías, productos y servicios (Wankel y F. Stoner, 2009).

El emprendimiento se ve favorecido por la existencia de las siguientes variables:

Variables ambientales: Existen factores de carácter ambiental, de tradiciones, económicos, políticos y sociales que tienden a favorecer o frenar el espíritu emprendedor. A ello se debe que en algunas naciones los empresarios emprendedores abunden mientras en otras haya escasez de estos.

Variables económicas: Ya que el espíritu emprendedor es esencialmente promotor del cambio económico (R. Stoner y Fry, 1982), los mismos factores que promueven el crecimiento económico y el desarrollo determinan el surgimiento del espíritu emprendedor (Wilken, 1979; Robles Álvarez, 2015). Se deben tener en cuenta dos tipos de factores: el primero relacionado con las oportunidades que brinde el mercado, visibles solo ante ojos emprendedores, y el segundo tipo relacionado con los recursos necesarios ya que se debe poseer cierta cantidad de capital tanto para la formación de un negocio como para la renovación de uno ya existente.

A mediados de la década de los 80 Begley et al. (1985), realizaron un estudio para distinguir entre individuos emprendedores y personas que administraban pequeños negocios arrojando como resultado la existencia de 5 dimensiones que caracterizaban al emprendedor: necesidad de triunfo, posición de control, tolerancia ante el riesgo, tolerancia ante la ambigüedad y tipo $\mathrm{A}$ de comportamiento ${ }^{3}$.

Lucas de Souza (2005), propone una matriz con las características de los individuos emprendedores para reunir los factores identificados en la revisión de la literatura relacionados a ese concepto, la cual fue el punto de partida y se actualizó con criterios de autores más recientes. Según los datos obtenidos, la característica innovación es considerada como factor identificativo por una serie de autores. Otros como de Souza, Fracasso, y Júnior (2008) y Sueiro Lopes y Souza (2006) la consideran una dimensión del perfil emprendedor, o sea, un componente general que agrupa varias características de menos significación individualmente, pues sus aportes tributan las dimensiones.

Turan y Kara (2007), investigaron las características de los emprendedores turcos y las compararon con las características de los emprendedores irlandeses a través de variables demográficas e informaciones de negocios, motivaciones, características emprendedoras, características personales y habilidades administrativas. Los resultados del estudio demostraron que las características tanto de los emprendedores irlandeses como las de los turcos eran similares y se resumían en: necesidad de realización, autoconfianza, persistencia, responsabilidad, asunción de desafíos, elevada autoestima, optimismo, rápida toma de decisiones, buena planeación y capacidad para enfrentar riesgos. Según la Management System International (Din, Anuar, y Usman, 2016), las características más representativas de los individuos emprendedores pueden ser agrupadas en tres grupos o dimensiones: realización, planeación y poder.

El estudio bibliográfico realizado posibilitó puntualizar que el emprendimiento está conformado por conocimientos, habilidades, experiencias, sentimientos, actitudes, motivaciones, características personales y valores que provocan un efecto sinérgico, por lo que emerge como una competencia del ser humano cuya manifestación en el ámbito del trabajo le confiere el

${ }^{3}$ Se refiere a aquella persona que el tiempo no le alcanza para satisfacer las necesidades personales de gloria y éxito. 
carácter de competencia. Los autores de esta investigación siguen los criterios de Sueiro Lopez y Lucas Souza (2006), y adoptan la concepción de las características que determinan el perfil emprendedor y las agruparon en cuatro dimensiones de acuerdo a su relación y a lo que tributan en cada dimensión. Éstas se describen a continuación:

Dimensión gestión: El conjunto de las características personales relacionadas con la capacidad de gestión de una persona que incluye las capacidades de gestión, organización, mando y control. Se vinculan a la administración de negocios, a la resolución de problemas, a la definición de metas y objetivos, a la búsqueda de informaciones y a la identificación de soluciones creativas para problemas concretos (Pedrosa, 2007). Significa "pensar antes de hacer, de forma sistemática, con métodos, analizar las ventajas y desventajas de cada acción emprendida, considerar los objetivos y resultados, es un conjunto de etapas que comprende: analizar el contexto, definir los objetivos, definir las estrategias para la ejecución de los medios de control, implementación, acompañamiento y validación" (Corona Armentats, Guimaraes, y Boly, 2007, p. 449). Se considera además su desarrollo en un marco ético y con la proactividad necesaria para visionar el futuro.

Dimensión negociación: El conjunto de las características que están relacionadas con la influencia del emprendedor en los resultados que quiere obtener y utilizar estrategias apropiadas de influencia y negociación (Pedrosa, 2007). Weber (2003), realizó un estudio acerca de la autoridad y el poder estableciendo como poder la imposición de la voluntad de una persona sobre un grupo o de un grupo sobre otro, forzando a alguien a hacer su voluntad, por causa de su posición de fuerza. Por el contrario, la negociación es la capacidad de hacer que las personas hagan de forma voluntaria lo que se les solicita, debido a su influencia personal. Es por ello, que en la investigación se asume el nombre de negociación a esta dimensión y se refiere a la capacidad de resolver conflictos eficazmente logrando el fortalecimiento de ambas partes, a partir de conciliar enfoques en función de la racionalización de los elementos positivos de determinadas ideas, criterios y voluntades, con el cuidado de mantener un clima estable, equilibrado y favorable ante las contingencias.

Dimensión realización: "La alta necesidad de realización obliga a las personas a que se comporten de forma que puedan desempeñar con éxito el papel emprendedor tal como fue definido por economistas, historiadores y psicólogos. Con motivo de su realización, los individuos tienden a procurar situaciones que proporcionen un desafío moderado (...) a desempeñar mejor sus tareas y a mostrar mayor confianza en las posibilidades de éxito". McClelland (1973), expresó que los individuos que poseen una gran necesidad de realización invierten tiempo pensando cómo trabajar mejor y cómo realizar las actividades que consideran importantes. Para Stewart et al. (2007)Stewart et al. (2007), la alta realización está caracterizada por el deseo de hacerlo todo de la mejor manera para sentirse realizado e impulsa al individuo a tomar decisiones emprendedoras. En la investigación se asume esta dimensión realización como la necesidad de realización que hace que las personas se comporten de forma que puedan desempeñar con éxito el papel emprendedor. Parte de que una alta realización está caracterizada por el deseo de hacerlo todo de la mejor manera y que sentirse realizado impulsa al individuo a tomar decisiones emprendedoras.

Dimensión innovación: Es la capacidad del capital humano de hacer algo nuevo, que las personas necesiten, que tenga valor y un mercado que lo quiera. Autores como Lawson y Samson (2001), proponen que la innovación "...representa una ventaja competitiva apoyada en la competencia, es el mecanismo por el cual se producen nuevos productos y procesos en las organizaciones, para resistir el proceso de transformaciones del mercado laboral con calidad, eficiencia, velocidad y eficacia. Los innovadores que poseen un alto desempeño pueden ofrecer 
productos de mayor calidad al mercado, de manera más rápida y a menores costos que los competidores".

Se trata de convertir las ideas en nuevos o mejorados bienes, servicios o procesos que el mercado valora, generar cambios tecnológicos y organizativos que aporten nuevas utilidades a la empresa y beneficios a la sociedad, estimular la creatividad buscando nuevas y mejores formas de hacer las cosas e integrando el pensamiento sistémico de los miembros de la organización. Se precisa de una adecuada combinación de trabajo individual y en equipo, en dependencia del reto creativo y de la etapa del proceso innovador, identificando problemas y posibles soluciones hasta su puesta en práctica (Lawson et al., 2001). En esta investigación se asume la dimensión innovación como las capacidades requeridas en el ser humano para producir nuevos procesos, productos y servicios en las organizaciones para resistir el proceso de transformaciones del mercado.

Las características correspondientes a cada dimensión y la explicación detallada de las mismas se expresan en la tabla 1.1

Tabla 1.1: Dimensiones y características definidas con su significado

\begin{tabular}{|c|c|c|}
\hline imensión & Características & Significado \\
\hline \multirow{6}{*}{ Gestión } & Integridad & $\begin{array}{l}\text { Capacidad para mantenerse dentro de las normas } \\
\text { sociales, organizacionales y éticas de las actividades } \\
\text { relacionadas con el trabajo }\end{array}$ \\
\hline & $\begin{array}{ll}\text { Planificación } & \text { y } \\
\text { Organización }\end{array}$ & $\begin{array}{l}\text { Muestra capacidad para proyectar el desarrollo de la } \\
\text { organización o parte de ella de forma realista, al } \\
\text { realizar planes, trazar objetivos y estrategias que } \\
\text { permitan alcanzar un desempeño exitoso en el } \\
\text { presente sobre la base de metas futuras. Es capaz de } \\
\text { establecer eficazmente un orden apropiado de } \\
\text { actuación personal o para terceros con el objetivo de } \\
\text { alcanzar una meta. }\end{array}$ \\
\hline & $\begin{array}{l}\text { Habilidad } \\
\text { control }\end{array}$ & $\begin{array}{l}\text { Utiliza eficazmente herramientas para el control de los } \\
\text { recursos y objetivos organizacionales a nivel táctico y } \\
\text { estratégico a partir de una planificación minuciosa de } \\
\text { la actividad. Implica la toma de decisiones que } \\
\text { aseguren este control. }\end{array}$ \\
\hline & Delegación & $\begin{array}{l}\text { A partir del conocimiento de las capacidades y } \\
\text { experiencias de sus subordinados, elige al más } \\
\text { competente y distribuye de manera eficaz las } \\
\text { funciones y tareas para el cumplimiento de los } \\
\text { objetivos de la organización. }\end{array}$ \\
\hline & Visión de futuro & $\begin{array}{l}\text { Es capaz de prever los medianos y grandes } \\
\text { acontecimientos mucho antes de que sucedan solo } \\
\text { con la observación de insignificantes variaciones del } \\
\text { entorno, está ligada a la adaptabilidad pero es más } \\
\text { profiláctica }\end{array}$ \\
\hline & $\begin{array}{l}\text { Actitud para el } \\
\text { cambio }\end{array}$ & $\begin{array}{l}\text { Es capaz de reconocer oportunamente la necesidad } \\
\text { del cambio ante situaciones problémicas. A partir de }\end{array}$ \\
\hline
\end{tabular}


su capacidad de influencia promueve y facilita procesos de cambio para el enfrentamiento a situaciones nuevas dentro de la organización.

Tolerancia al Se refiere a la capacidad de mantener en todo estrés momento firme y estable el carácter bajo presión y/u oposición, siendo capaz de dar respuestas controladas en situaciones de estrés.

Negociación Flexibilidad La posibilidad de adaptarse y de trabajar en una amplia gama de situaciones, individuales o de grupo, manteniendo el rumbo, adaptándose a las situaciones novedosas que se encuentran en el camino, asumiéndolas con la actitud de aprovechar al máximo cada una de ellas.

Independencia Es capaz de actuar sobre la base de sus propias convicciones en lugar de en el deseo de agradar a terceros. Disposición para poner en duda un clima de opinión o una línea de acción.

Liderazgo Es capaz de aglutinar, conducir, definir estilos conductuales y normas de comportamiento hacia la consecución de los objetivos organizacionales, a partir de su ejemplo individual, ocupando un lugar significativo dentro del grupo y con la utilización de los rasgos y métodos interpersonales más apropiados para guiar a individuos o grupos hacia la consecución de objetivos.

Capacidad crítica Habilidad para la evaluación de datos y líneas de y autocrítica actuación, así como para tomar decisiones lógicas de una manera imparcial y desde un punto de vista racional.

Escucha Es la capacidad de recibir, procesar, sintetizar y traducir óptimamente los mensajes comunicativos emitidos, manteniendo una atención continua sobre el emisor y eliminando las ambigüedades e interpretaciones incorrectas que pudieran surgir durante el intercambio.

\begin{tabular}{ll}
\hline Trabajo en & Disposición para participar como miembro \\
equipo & totalmente integrado en un equipo del cual no se \\
& tiene por qué ser necesariamente el jefe; colaborador \\
& eficaz incluso cuando el equipo se encuentra \\
& trabajando en algo que no está directamente \\
& relacionado con sus intereses personales. \\
\hline Responsabilidad & $\begin{array}{l}\text { Compromiso activo y libre para medir consecuencias } \\
\text { de las acciones y responder de ellas ante sí mismo y } \\
\text { los demás. }\end{array}$ \\
\hline Automotivación & $\begin{array}{l}\text { Se traduce en la importancia de hacer las cosas para } \\
\text { conseguir una satisfacción personal. Necesidad de }\end{array}$ \\
\hline
\end{tabular}


alcanzar un objetivo con éxito.

Tenacidad Es la capacidad para perseverar en un asunto o problema hasta comprobar que este quede resuelto y hasta comprobar que el objetivo no es alcanzable en un período razonable.

Meticulosidad Se refiere a resolución total de una tarea o asunto hasta el final y en todas las áreas que envuelva, independientemente de su insignificancia.

Análisis de Está dirigida a la eficacia a la hora de identificar un problemas problema, buscar datos pertinentes al respecto,

Realización reconocer la información relevante y encontrar las posibles causas del mismo. Es capaz de realizar un eficiente procesamiento de la información en el que interviene la capacidad de razonamiento, fluidez de ideas, evaluación de datos, comparación sistemática y generación de alternativas, establecimiento de prioridades e identificación de las relaciones causa efecto que ocurren, que le permiten llegar a conclusiones lógicas de forma oportuna.

Asumir riesgos Es la capacidad para asumir acciones que envuelvan un riesgo deliberado con el objeto de lograr un beneficio o una ventaja importante.

Persistencia Capacidad para generar, mantener y comprometerse
con una visión de mediano plazo, apegándose creativamente a ella en medio de los vaivenes producidos por la variedad de situaciones que la persona y la organización encuentran en el desarrollo de su idea.

Pragmatismo Es la capacidad de orientarse a acciones concretas, reales y prácticas. Permite materializar los proyectos.

Oportuno Capacidad desarrollada para ver en su momento oportunidades que se le presentan, tomar las que considere mejores y asumir los riesgos calculados que éstas oportunidades implican. Considera los fracasos como aprendizajes que producen lecciones para continuar impulsándose.

Tipo A de Considera que el tiempo no le alcanza para satisfacer comportamiento las necesidades personales de gloria y éxito, que cultiven la personalidad.

Actitud inconform ' Se refiere a la actitud de inconformidad ante cualquier resultado, se trata de la característica personal de constantemente desafiar el estatus alcanzado

Iniciativa Está dirigida a la influencia activa en los acontecimientos en lugar de aceptación pasiva de los mismos, es la visión de oportunidades en ellos. Da lugar a la acción. Muestra una disposición positiva para 
realizar sus actividades y alcanzar sus propósitos Innovación emprendiendo acciones y creando oportunidades para lograr la mejora de su desempeño y el de la organización.

Creatividad

Es la capacidad para generar respuestas innovadoras a las situaciones complejas que se le presentan, de manera que produzca soluciones originales o poco habituales, que enriquezcan su proceso generador de riqueza y prosperidad.

Una vez analizadas las definiciones dadas por diversos autores y los estudios precedentes, los autores consideran necesario definir el emprendimiento como competencia de la siguiente manera:

Es la integración sinérgica de gestión, negociación, realización e innovación que se manifiesta en un individuo al ejecutar una actividad laboral determinada, que se materializa en un desempeño laboral superior por lo que contribuye a la mejora y sostenibilidad de los procesos productivos y de servicios, en correspondencia con las exigencias políticas, sociales, ambientales, tecnológicas y económicas del entorno en que se desenvuelve.

Esta definición se refiere a una competencia individual que se manifiesta o se desarrolla en las personas que laboran en una organización. Para ello es necesario impulsar procesos de gestión, que una vez materializados en los individuos, comience a expandirse como una presunción básica compartida en todos los miembros. El anclaje de la misma como valor organizacional configura un elemento de la cultura organizacional que finalmente es el objetivo supremo: contar con organizaciones emprendedoras que contribuyan al desarrollo socioeconómico del territorio o país. De ahí la necesidad de desarrollar una cultura emprendedora a partir de capital humano emprendedor suficiente para alcanzar las metas propuestas y lograr así el desarrollo de las organizaciones.

La formación de la cultura emprendedora implica el desarrollo del emprendimiento como competencia, que es la fuerza interior que permite a las personas dado un entorno fijarse nuevas metas y ser capaces de construirlas, tener iniciativa, afrontar con fortaleza los problemas y resolverlos de manera creativa, sortear las dificultades y aprovechar las oportunidades con un alto sentido ético y de responsabilidad social.

\section{METODOLOGÍA}

1.2 2.1. Contextualización de las dimensiones y características del emprendimiento a Cuba

Una vez analizado el marco teórico referencial, se consideró necesario establecer la pertinencia de la propuesta de dimensiones y características al contexto cubano. Para ello se utilizó un grupo de trabajadores por cuenta propia del municipio Holguín, cuyas actividades tienen el mayor número de licencias concedidas y cuyos negocios llevan más de cinco años de funcionamiento con resultados exitosos, así como trabajadores de empresas estatales líderes en el territorio que han recibido premios provinciales o nacionales de innovación así como certificaciones en alguno o varios sistemas de gestión. Se consideró además la información brindada por la ONAT (37505 TCP hasta diciembre 2016) y se escogieron las actividades que tienen más de 250 licencias concedidas. 
El tamaño de muestra (tabla 2.1 y 2.2), fue distribuido de manera que abarcara las diferentes actividades seleccionadas ${ }^{4}$.

Tabla 2.1: Muestra seleccionada en actividades del sector no estatal

\begin{tabular}{lcc}
\hline Actividad & $\begin{array}{c}\text { Cantidad de licencias } \\
\text { concedidas }\end{array}$ & Muestra \\
\hline Arrendador de habitaciones & 730 & 13 \\
\hline Artistas independientes & 402 & 8 \\
\hline Artistas de cualquier manifestación & 2238 & 37 \\
\hline Transportador de pasajeros & 792 & 13 \\
\hline Trabajador contratado & 3755 & 63 \\
\hline Agentes de telecomunicaciones & 424 & 7 \\
\hline Elaborador vendedor de alimentos y bebidas & 1049 & 17 \\
\hline $\begin{array}{l}\text { Elaborador vendedor de alimentos y bebidas en } \\
\text { puntos fijos de venta }\end{array}$ & 288 & 6 \\
\hline Cafetería de alimentos ligeros & 810 & 14 \\
\hline Comprador vendedor de discos & 485 & 9 \\
\hline $\begin{array}{l}\text { Elaborador vendedor de artículos varios de usos } \\
\text { en el hogar }\end{array}$ & 994 & 17 \\
\hline Total & 11967 & 204 \\
\hline
\end{tabular}

Tabla 2.2. Muestra seleccionada en empresas del sector estatal

\begin{tabular}{lc}
\hline Empresa & Muestra \\
\hline CUPET & 7 \\
\hline Empresa de Cigarros & 10 \\
\hline Vértice & 9 \\
\hline Serconi & 12 \\
\hline Raudal & 8 \\
\hline Desoft & 10 \\
\hline Total & 56 \\
\hline
\end{tabular}

Con la finalidad de que los 260 participantes en el estudio emitieran su criterio sobre la pertinencia o no en el entorno cubano de las 26 características y las 4 dimensiones, definidas por diversos autores en el marco teórico, se elaboró y aplicó un instrumento (tabla 2.3). El procesamiento de la información se realizó con el uso de la técnica multivariante de análisis de conglomerados y con el programa Statgraphics Versión 8 (su salida se adecua a los intereses de investigación al permitir definir el número de clúster, en este caso se emplean cuatro por ser el número de dimensiones definidas con anterioridad) mediante el método centroide y de distancia euclidea para las variables.

\footnotetext{
4 Para la selección de las actividades se utilizó el muestreo no probabilístico intencional, y para la aplicación de las encuestas de manera aleatoria dentro de cada actividad. De manera intencionada fueron escogidas las actividades reconocidas para el sector no estatal que tienen el mayor número de licencias concedidas y cuyos negocios llevan más de cinco años de funcionamiento con resultados exitosos. El procesamiento de los resultados SPSS versión 21, para los datos primarios de variables con un nivel de medición ordinal para obtener la estadística descriptiva que permitiría conocer las respuesta de cada categoría ordinal y tomar decisiones.
} 
Tabla 2.3: Instrumento aplicado para contextualizar características y dimensiones al contexto cubano.

Estimado(a) señor(a), la Universidad de Holguín, se encuentra realizando una investigación acerca del emprendimiento como competencia en el capital humano, usted ha sido seleccionado para conocer su criterio acerca de las características que en nuestro entorno cubano debe poseer una persona para considerarse emprendedora, así como la dimensión que se considera las agrupan.

Criterio: 1 si se ajusta a nuestro contexto cubano $\mathbf{0}$ si no se ajusta y debe ser eliminada

\section{Características}

Criterio Dimensión Criterio

Tolerancia al estrés: Mantenimiento firme del carácter bajo presión y/o oposición. Se traduce en respuestas controladas en situaciones de estrés.

Flexibilidad Capacidad desarrollada para moverse entre diferentes situaciones, manteniendo el norte y adaptándose a las situaciones novedosas que se encuentran en el camino, asumiéndolas con una actitud de sacar el mayor provecho de cada una de ellas

Tenacidad: Capacidad para perseverar en un asunto o problema hasta comprobar que este quede resuelto y hasta comprobar que el objetivo no es alcanzable en un período razonable

Independencia: Actuación basada en las propias convicciones en lugar de en el deseo de agradar a terceros. Disposición para poner en duda un clima de opinión o una línea de acción

Integridad : Capacidad para mantenerse dentro de las normas sociales, organizacionales y éticas de las actividades relacionadas con el trabajo

Meticulosidad Resolución total de una tarea o asunto hasta el final y en todas las áreas que envuelva, independientemente de su insignificancia

Planificación y organización: Capacidad para establecer eficazmente un orden apropiado de actuación personal o para terceros con el objetivo de alcanzar una meta

Habilidad de control: Reconocimiento de la necesidad de control y del mantenimiento de éste sobre métodos, personas y situaciones. Implica la toma de decisiones que aseguren este control

Delegación: Distribución eficaz de la toma de decisiones y de otras responsabilidades

Liderazgo: Utilización de los rasgos y métodos interpersonales más apropiados para guiar a individuos o grupos hacia la consecución de objetivos

Capacidad crítica y autocrítica: Habilidad para la evaluación de datos y líneas de actuación, así como para tomar decisiones lógicas de una manera imparcial y desde un punto de vista racional

\begin{tabular}{|l|l|l|}
\hline Negociación & \\
\hline & Regociación & \\
\hline & Negociación & \\
\hline & Gestión & \\
\hline Gestión & \\
\hline & Gestión & \\
\hline & Gestión & \\
\hline & & \\
\hline & & \\
\hline
\end{tabular}




\begin{tabular}{|c|c|}
\hline $\begin{array}{l}\text { Análisis de problemas: Eficacia a la hora de identificar un problema, } \\
\text { buscar datos pertinentes al respecto, reconocer la información relevante y } \\
\text { encontrar las posibles causas del mismo }\end{array}$ & Realización \\
\hline $\begin{array}{l}\text { Creatividad: Capacidad para generar respuestas innovadoras a las } \\
\text { situaciones complejas que se le presentan, de manera que produzca } \\
\text { soluciones originales o poco habituales, que enriquezcan su proceso de } \\
\text { generador de riqueza y prosperidad }\end{array}$ & Innovación \\
\hline $\begin{array}{l}\text { Asumir riesgos: Capacidad para asumir acciones que envuelvan un } \\
\text { riesgo deliberado con el objeto de lograr un beneficio o una ventaja } \\
\text { importante }\end{array}$ & Realización \\
\hline $\begin{array}{l}\text { Escucha: Capacidad para entresacar la información importante de una } \\
\text { comunicación oral. Las preguntas aclaratorias y esperar que el otro finalice } \\
\text { demuestran una escucha "activa }\end{array}$ & Negociación \\
\hline $\begin{array}{l}\text { Trabajo en equipo: Disposición para participar como miembro totalmente } \\
\text { integrado en un equipo del cual no se tiene por qué ser necesariamente el } \\
\text { jefe; colaborador eficaz incluso cuando el equipo se encuentra trabajando } \\
\text { en algo que no está directamente relacionado con intereses personales }\end{array}$ & Negociación \\
\hline $\begin{array}{l}\text { Iniciativa: Influencia activa en los acontecimientos en lugar de aceptación } \\
\text { pasiva de los mismos, visión de oportunidades en ellos. Da lugar a la } \\
\text { acción. }\end{array}$ & Innovación \\
\hline $\begin{array}{l}\text { Responsabilidad: Compromiso activo y libre para medir consecuencias } \\
\text { de las acciones y responder de ellas ante sí mismo y los demás. }\end{array}$ & Negociación \\
\hline $\begin{array}{l}\text { Persistencia: Capacidad para generar, mantener y comprometerse con } \\
\text { una visión de mediano plazo, apegándose creativamente a ella en medio } \\
\text { de los vaivenes producidos por la variedad de situaciones que la persona } \\
\text { y la organización encuentran en el desarrollo de su idea. }\end{array}$ & Realización \\
\hline $\begin{array}{l}\text { Pragmatismo: Orientación a resultados concretos. Materializa los } \\
\text { proyectos. }\end{array}$ & Realización \\
\hline $\begin{array}{l}\text { Automotivación: Se traduce en la importancia de hacer las cosas para } \\
\text { conseguir una satisfacción personal. Necesidad de alcanzar un objetivo } \\
\text { con éxito }\end{array}$ & Negociación \\
\hline $\begin{array}{l}\text { Oportuno: Capacidad desarrollada para ver en su momento } \\
\text { oportunidades que se le presentan, tomando las que considere mejores y } \\
\text { asumiendo los riesgos calculados que éstas oportunidades implican. } \\
\text { Considera los fracasos como aprendizajes que producen lecciones para } \\
\text { continuar impulsándose }\end{array}$ & Realización \\
\hline $\begin{array}{l}\text { Tipo A de comportamiento: considera que el tiempo no le alcanza para } \\
\text { satisfacer las necesidades personales de gloria y éxito, que cultiven la } \\
\text { personalidad }\end{array}$ & Realización \\
\hline
\end{tabular}




\begin{tabular}{|l|l|l|l|}
\hline $\begin{array}{l}\text { Actitud disconforme: se refiere a la aptitud de disconformidad ante } \\
\text { cualquier resultado, se trata de la característica personal de } \\
\text { constantemente desafiar el estatus quo }\end{array}$ & Realización & \\
\hline $\begin{array}{l}\text { Visión de futuro: Capacidad para prever los medianos y grandes } \\
\text { acontecimientos mucho antes de que sucedan solo con la observación de } \\
\text { insignificantes variaciones del entorno, está ligada a la adaptabilidad pero } \\
\text { es más profiláctica }\end{array}$ & Gestión & & \\
\hline $\begin{array}{l}\text { Actitud para el cambio: capacidad para fomentar la transición que ocurre } \\
\text { cuando se transita de un estado a otro }\end{array}$ & Gestión & \\
\hline
\end{tabular}

Sugerencia de otras características que no se encuentren descritas en la tabla y sean necesarias para ser emprendedor en Cuba.

Así como otros criterios que desee emitir:

\section{RESULTADOS OBTENIDOS}

El instrumento se aplicó en una primera ronda apreciándose problemas de comprensión y en el empleo de la escala valorativa, por lo que fue necesario aplicar una segunda ronda. Después de realizar un proceso de capacitación, se cambió la escala y se añadió una pregunta general que da la posibilidad de añadir o eliminar características. Como resultado final se obtuvo que solo en 10 casos se añadió la honradez como una nueva característica, 130 eliminaron meticulosidad (50\%), los 260 eliminaron Tipo A de comportamiento y 158 persistencia (60,7\%). Se decidió no añadir honradez y eliminar estas tres últimas características. Al final resultaron 23 características a considerar. En la figura 2.1 se muestra la salida del Statgraphics Versión 8 con el análisis clúster desarrollado.

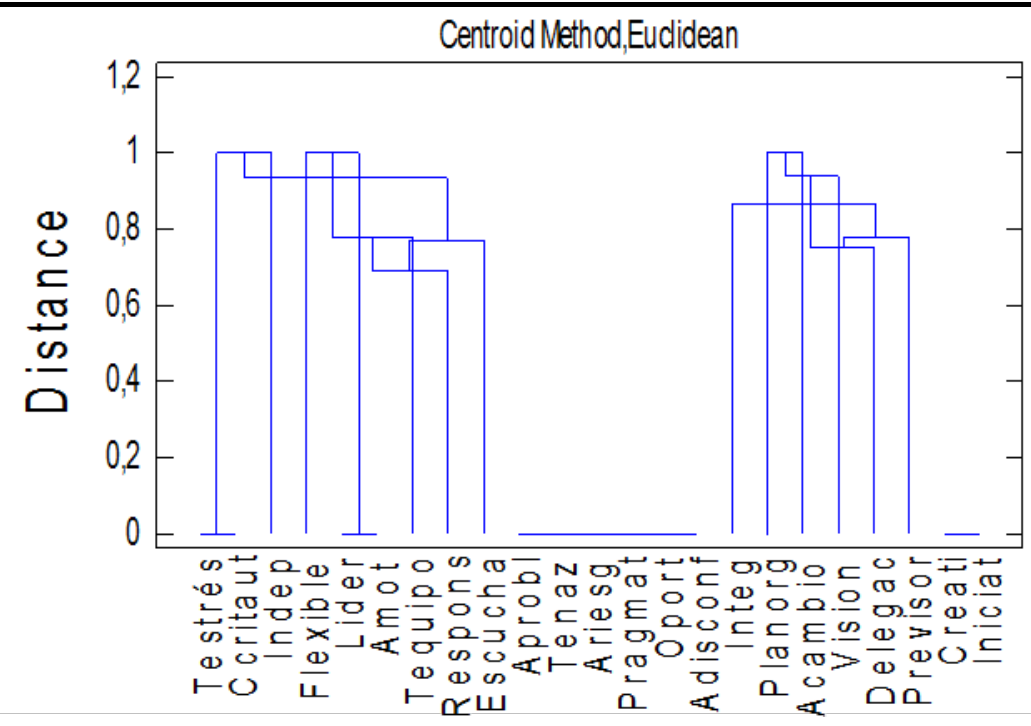

Figura 2.1: Análisis clúster que relaciona características con dimensiones del emprendimiento en el contexto cubano.

Como se puede apreciar en el clúster 1 se sitúan 9 variables que representan el 39,13 \% del total: tolerancia al estrés, capacidad crítica y autocrítica, flexibilidad, independencia, 
responsabilidad, automotivación, liderazgo, escucha, trabajo en equipos, las que serán consideradas en la dimensión negociación. En el clúster 2 se sitúan 6 variables que representan el $26,08 \%$ del total: integridad, planificación y organización, actitud para el cambio, habilidad de control, delegación y visión de futuro las que serán consideradas en la dimensión gestión.

En el clúster 3 se sitúan 6 variables que representan el 26,08 \% del total: tenacidad, asumir riesgos, pragmatismo, análisis de problemas, oportuno y actitud inconforme las que serán consideradas en la dimensión realización. En el clúster 4 se sitúan 2 variables que representan el 8,69 \% del total: creatividad e iniciativa, las que serán consideradas en la dimensión innovación. De esta forma quedan agrupadas las variables que conforman cada dimensión del emprendimiento como competencia en el contexto cubano y que son las utilizadas en la investigación. La descripción del comportamiento asociado a cada dimensión y característica fueron redactadas y se conformó el modelo genérico para el emprendimiento como competencia del capital humano (tabla 2.4) . Se ubicó dentro de cada dimensión la descripción de las características seleccionadas para ella, que muestran las pautas del comportamiento asociado a esta competencia.

Tabla 2.4. Modelo genérico del emprendimiento como competencia del capital humano en el contexto cubano.

\section{DIMENSIÓN GESTIÓN (G)}

Está referida a la capacidad de gestión de una persona, que incluye las capacidades de planeación, organización, mando y control. Se vinculan a la administración de negocios, a la resolución de problemas, a la definición de metas y objetivos, a la búsqueda de informaciones y a la identificación de soluciones creativas para problemas concretos. Significa "pensar antes de hacer, de forma sistemática, con métodos, analizando ventajas y desventajas de cada acción emprendida, considerando objetivos y resultados, es un conjunto de etapas que comprende: analizar el contexto, definir los objetivos, definir las estrategias para la ejecución de los medios de control, implementación, acompañamiento y validación. Está formada por 6 características

\begin{tabular}{l|l}
\hline G1 & $\begin{array}{l}\text { Integridad: Es la capacidad para mantenerse dentro de las normas sociales, } \\
\text { organizacionales y éticas de las actividades relacionadas con el trabajo. }\end{array}$ \\
\hline $\mathbf{G 2}$ & $\begin{array}{l}\text { Planeación y Organización: Muestra capacidad para proyectar el desarrollo de la } \\
\text { organización o parte de ella de forma realista, realizando planes, trazando objetivos } \\
\text { y estrategias que permitan alcanzar un desempeño exitoso en el presente sobre la } \\
\text { base de metas futuras, es capaz de establecer eficazmente un orden apropiado de } \\
\text { actuación personal o para terceros con el objetivo de alcanzar una meta. }\end{array}$ \\
\hline $\mathbf{G 3}$ & $\begin{array}{l}\text { Habilidad de control: Utiliza eficazmente herramientas para el control de los } \\
\text { recursos y objetivos organizacionales a nivel táctico y estratégico a partir de una } \\
\text { planificación minuciosa de esta actividad. }\end{array}$ \\
\hline $\mathbf{G 4}$ & $\begin{array}{l}\text { Delegación: A partir del conocimiento de las capacidades y experiencias de sus } \\
\text { subordinados elige al más competente y distribuye eficazmente funciones y tareas } \\
\text { para el cumplimiento de los objetivos organizacionales. }\end{array}$ \\
\hline $\mathbf{G 5}$ & $\begin{array}{l}\text { Visión de futuro: Es capaz de prever los medianos y grandes acontecimientos mucho } \\
\text { antes de que sucedan solo con la observación de insignificantes variaciones del } \\
\text { entorno, está ligada a la adaptabilidad pero es más profiláctica. }\end{array}$ \\
\hline
\end{tabular}


Actitud para el cambio: Es capaz de reconocer oportunamente la necesidad del cambio ante situaciones problémicas. A partir de su capacidad de influencia promueve y facilita procesos de cambio para el enfrentamiento a situaciones nuevas dentro de la organización.

\section{DIMENSIÓN NEGOCIACIÓN (N)}

Se refiere a la capacidad de resolver conflictos eficazmente logrando el favorecimiento de ambas partes, a partir de conciliar enfoques en función de la racionalización de los elementos positivos de determinadas ideas, criterios, voluntades, cuidando mantener un clima estable, equilibrado y abierto ante las contingencias. Está relacionado con la influencia del emprendedor en los resultados que quiere obtener y utilizar estrategias apropiadas de influencia y negociación. Está formada por 9 características

Tolerancia al estrés: Mantiene en todo momento firme y estable su carácter bajo

N1 presión y (u) oposición, siendo capaz de dar respuestas controladas en situaciones de máximo estrés.

Flexibilidad: Es capaz de adaptarse y de trabajar en una amplia variedad de

N2 situaciones, individuales o de grupo, manteniendo el rumbo, adaptándose a las situaciones novedosas que se encuentran en el camino, asumiéndolas con una actitud de sacar el mayor provecho de cada una de ellas.

Independencia: Es capaz de actuar sobre la base de sus propias convicciones en

N3 lugar de en el deseo de agradar a terceros. Disposición para poner en duda un clima de opinión o una línea de acción.

Liderazgo: Es capaz de aglutinar, conducir, definir estilos conductuales y normas de comportamiento, hacia la consecución de los objetivos organizacionales a partir de

N4 su ejemplo individual ocupando un lugar significativo dentro del grupo y con la utilización de los rasgos y métodos interpersonales más apropiados para guiar a individuos o grupos hacia la consecución de objetivos.

Capacidad crítica y autocrítica: Habilidad para la evaluación de datos y líneas de

N5 actuación, así como para tomar decisiones lógicas de una manera imparcial y desde un punto de vista racional.

Escucha: Es capaz de recibir, procesar, sintetizar y traducir óptimamente los

N6 mensajes comunicativos emitidos, manteniendo una atención continua sobre el emisor, y eliminando las ambigüedades e interpretaciones incorrectas que pudieran surgir durante el intercambio.

Trabajo en equipo: Disposición para participar como miembro totalmente integrado

N7 en un equipo del cual no se tiene por qué ser necesariamente el jefe; colaborador eficaz incluso cuando el equipo se encuentra trabajando en algo que no está directamente relacionado con sus intereses personales.

N8 Responsabilidad: Compromiso activo y libre para medir consecuencias de las acciones y responder de ellas ante sí mismo y los demás.

N9

Automotivación: Se traduce en la importancia de hacer las cosas para conseguir una satisfacción personal. Necesidad de alcanzar un objetivo con éxito.

\section{DIMENSIÓN REALIZACIÓN (R)}


Está dirigida a la alta necesidad de realización que hace que las personas se comporten de forma que puedan desempeñar con éxito el papel emprendedor. Parte de que una alta realización está caracterizada por el deseo de hacerlo todo de la mejor manera, sentirse realizado, impulsa al individuo a tomar decisiones emprendedoras. Está formada por 6 características

\begin{tabular}{c|l}
\hline R1 & $\begin{array}{l}\text { Tenacidad: Es la capacidad que posee un individuo para perseverar en un asunto o } \\
\text { problema hasta comprobar que este quede resuelto y hasta comprobar que el } \\
\text { objetivo no es alcanzable en un período razonable. }\end{array}$ \\
\hline $\mathbf{R 2}$ & $\begin{array}{l}\text { Análisis de problemas: Es capaz de realizar un eficiente procesamiento de la } \\
\text { información en el que interviene la capacidad de razonamiento, fluidez de ideas, } \\
\text { evaluación de datos, comparación sistemática y generalizar alternativas, establecer } \\
\text { prioridades e identificar las relaciones causa efecto que ocurren, que le permiten } \\
\text { Ilegar a conclusiones lógicas de forma oportuna. Se refiere a la eficacia al identificar } \\
\text { un problema, buscar datos pertinentes al respecto, reconocer la información } \\
\text { relevante y encontrar las posibles causas del mismo. }\end{array}$ \\
\hline $\mathbf{R 3}$ & $\begin{array}{l}\text { Asumir riesgos: Capacidad para asumir acciones que envuelvan un riesgo deliberado } \\
\text { con el objeto de lograr un beneficio o una ventaja importante. }\end{array}$ \\
\hline $\mathbf{R 4}$ & $\begin{array}{l}\text { Pragmatismo: Es la capacidad de orientarse a acciones concreta, reales y prácticas. } \\
\text { Permite materializar los proyectos. }\end{array}$ \\
\hline $\mathbf{R 5}$ & $\begin{array}{l}\text { Oportuno: Capacidad desarrollada para ver en su momento oportunidades que se le } \\
\text { presentan, tomando las que considere mejores y asumiendo los riesgos calculados } \\
\text { que estas oportunidades implican. Considera los fracasos como aprendizajes que } \\
\text { producen lecciones para continuar impulsándose. }\end{array}$ \\
\hline R6 & $\begin{array}{l}\text { Actitud inconforme: Se refiere a la actitud de disconformidad ante cualquier } \\
\text { resultado, se trata de la característica personal de constantemente desafiar el } \\
\text { estatus. }\end{array}$ \\
\hline
\end{tabular}

\section{DIMENSIÓN INNOVACIÓN (I)}

Está dirigida a las capacidades requeridas en el ser humano para producir nuevos productos, servicios y procesos en las organizaciones, para resistir el proceso de transformaciones del mercado.

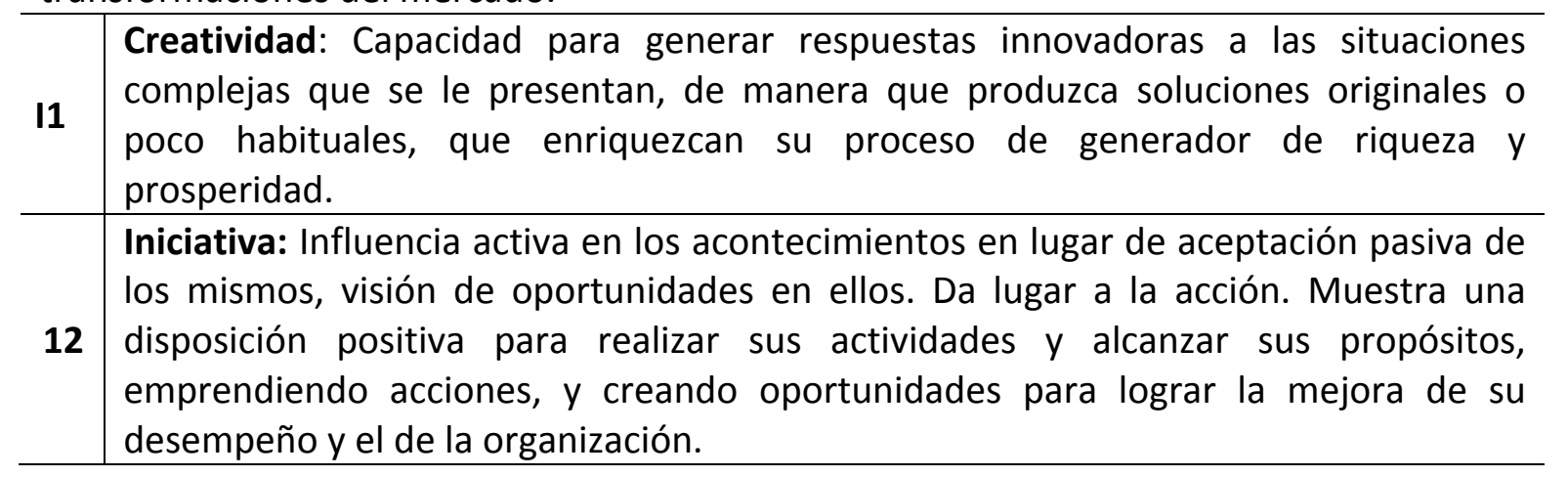

\section{CONCLUSIONES}

En la literatura consultada los criterios son diversos al definir las características que conforman el emprendimiento, constituye una regularidad su visión como el comportamiento que se necesita para dar inicio a una actividad económica. 
El estudio bibliográfico realizado posibilitó puntualizar que el emprendimiento está conformado por conocimientos, habilidades, experiencias, sentimientos, actitudes, motivaciones, características personales y valores que provocan un efecto sinérgico, por lo que emerge como una competencia del ser humano cuya manifestación en el ámbito del trabajo le confiere el carácter de competencia.

Se arriba a una nueva conceptualización del emprendimiento como competencia del capital humano definido como: la integración sinérgica de gestión, negociación, realización e innovación que se manifiesta en un individuo al ejecutar una actividad laboral determinada, que se materializa en un desempeño laboral superior por lo que contribuye a la mejora y sostenibilidad de los procesos productivos y de servicios, en correspondencia con las exigencias políticas, sociales, ambientales, tecnológicas y económicas del entorno en que se desenvuelve.

En el contexto cubano se reconoce la presencia de las 4 dimensiones identificadas, con 23 de las características estudiadas y se conforma el modelo genérico del emprendimiento como competencia del capital humano en Cuba.

Las fuentes consultadas, centran sus análisis en el emprendimiento como una cualidad individual, obviando su influencia en la conformación de una cultura emprendedora que contribuye a la mejora y sostenibilidad de las metas organizacionales.

\section{REFERENCIAS}

Alvarez, J. G., Losada, A. S., y Comesaña, J. M. C. (2014). Prospects for Social Employment Insertion of Graduates in Pedagogy in the Autonomous Community of Galicia. From the University to the Labour Market. Procedia - Social and Behavioral Sciences, 139, 412-418. doi: http://dx.doi.org/10.1016/j.sbspro.2014.08.028

Álvarez Santos, L., y Anglés Peña, M. d. L. (2012). Aplicación de una tecnología para el desarrollo integrado de competencias laborales en la Universidad de Holguín Oscar Lucero Moya. Ingeniería Industrial. Holguín.

Allali, B. (2010). Intrapreneuriality and the perceived autonomy indicators. International Journal of Entrepreneurship and Small Business, 10(3), 324-338.

Alles, M. A. (2006). Dirección estratégica de recursos humanos: gestión por competencias (Vol. 1): Ediciones Granica S.A.

Audretsch, D. B. (1999). Entrepreneurship and economic restructuring: an evolutionary view. Entrepreneurship, small \& medium-sized enterprises and the macroeconomy. Cambridge University Press, Cambridge, 79-96.

Begley, T. M., y Boyd, D. P. (1985). The relationship of the Jenkins Activity Survey to Type A behavior among business executives. Journal of Vocational Behavior, 27(3), 316-328.

Bikse, V., Rivza, B., y Riemere, I. (2015). The Social Entrepreneur as a Promoter of Social Advancement. Procedia - Social and Behavioral Sciences, 185, 469-478. doi: http://dx.doi.org/10.1016/j.sbspro.2015.03.405

Blanchflower, D. G., y Oswald, A. J. (1998). What makes an entrepreneur? Journal of labor Economics, 16(1), 26-60.

Boyatzis, R. E. (1982). The competent manager: A model for effective performance: John Wiley \& Sons.

Butler, J. S. (2012). Entrepreneurship and self-help among black Americans: A reconsideration of race and economics: SUNY Press.

Caldera, J., Rodríguez, F., y Moreno, J. (2013). El desarrollo de capacidades emprendedoras. 
Camelo-Ordaz, C., Diánez-González, J. P., y Ruiz-Navarro, J. (2016). The influence of gender on entrepreneurial intention: The mediating role of perceptual factors. BRQ Business Research Quarterly, 19(4), 261-277. doi: http://dx.doi.org/10.1016/j.brq.2016.03.001

Castillo, A. (1999). Estado del Arte del emprendimiento. Intec Chile.

Collins, O. F., Moore, D. G., y Unwalla, D. (1964). The enterprising man and the business executive. MSU Business Topics, 12(1), 19-34.

Corona Armentats, J. R., Guimaraes, L. M., y Boly, V. (2007). A Methodology To Measure The Innovation Process Capacity In Enterprises. Challenges in the Management of New Technologies, 1.

Cowling, A., Newman, K., y Leigh, S. (1999). Developing a competency framework to support training in evidence-based healthcare. International Journal of Health Care Quality Assurance, $12(4), 149-160$.

Cuesta Santos, A. R. (2008). Tecnología de Gestión de Recursos Humanos y del Conocimiento. Editorial: Artes Gráficas del Valle Ltda., Cali-Colombia.

Cuesta Santos, A. R. (2010). Gestión del conocimiento: análisis y proyección de los recursos humanos: Editorial Academia.

Cuesta Santos, A. R. (2011). Metodología de Gestión por Competencias Asumiendo la Norma Cubana sobre Gestión del Capital Humano/Metodologia de Gestao por Competencias Assumindo a Norma Cubana sobre Gestao de Capital Humano/Methodology of Competences Management Assuming the Cuban Norm about Management of Human Capital. Revista Brasileira de Gestão de Negócios, 13(40), 300-300.

Cuesta Santos, A. R., y Valencia Rodríguez, M. (2018). Capital Humano: Contexto de su gestión. Desafíos para Cuba. Ingeniería Industrial, XXXIV(2), 135-145.

Chye Koh, H. (1996). Testing hypotheses of entrepreneurial characteristics: A study of Hong Kong MBA students. Journal of managerial Psychology, 11(3), 12-25.

de Souza, E. C. L., Fracasso, E. M., y Júnior, G. S. L. (2008). Empreendedorismo e atitude empreendedora: conceitos e construção de escalas.

Díaz Barriga, F., y Hernández Rojas, G. (2002). Estrategias de enseñanza para la promoción de aprendizajes significativos. Estrategias docentes para un aprendizaje significativo. Una interpretación constructivista. México: McGraw-Hill, 137-230.

Din, B., Anuar, A. R., y Usman, M. (2016). The Effectiveness of the Entrepreneurship Education Program in Upgrading Entrepreneurial Skills among Public University Students. Procedia Social and Behavioral Sciences, 224, 117-123. doi: http://dx.doi.org/10.1016/j.sbspro.2016.05.413

Draghici, A., y Albulescu, C. T. (2014). Does the Entrepreneurial Activity Enhance the National Innovative Capacity? Procedia - Social and Behavioral Sciences, 124, 388-396. doi: http://dx.doi.org/10.1016/j.sbspro.2014.02.500

Drucker, P. (1985). Purposeful Innovation and the Seven Sources for Innovative Opportunity. Innovation and Entrepreneurship: Practice and Principles, 30-36.

Duque Ceballos, J. L., García Solarte, M., y Hurtado Ayala, A. (2017). Influencia de la inteligencia emocional sobre las competencias laborales: un estudio con empleados del nivel administrativo. Estudios Gerenciales, 33.

Fandiño, L., y Bolívar, M. (2008). Evaluación del impacto del emprendimiento empresarial en los estudiantes y/o egresados de la carrera de Administración de Empresas de la Pontificia Universidad Javeriana y estudio de los factores de éxito de sus empresas creadas a partir de los talleres de grado. Universidad Javeriana. Bogotá. 
Ferreira, A. d. S. M., Loiola, E., y Gondim, S. M. G. (2017). Motivations, business planning, and risk management: entrepreneurship among university students. RAI Revista de Administração e Inovação, 14(2), 140-150. doi: http://doi.org/10.1016/j.rai.2017.03.003

Gámez Gutiérrez, J., y Garzón Baquero, J. E. (2017). New cross-proposal entrepreneurship and innovation in educational programs in third level (tertiary) education. Contaduría y Administración, 62(1), 239-261. doi: http://dx.doi.org/10.1016/j.cya.2016.10.005

García, G. (2002). Saénz y Sepúlveda. Formaci\{\'o\}n de Emprendedores.

García, P. O., y Capitán, Á. O. (2016). Elements that contribute to boost female entrepreneurship: A prospective analysis. Suma de Negocios, 7(15), 54-60. doi: http://dx.doi.org/10.1016/j.sumneg.2016.02.003

Gedik, S.., Miman, M., y Kesici, M. S. (2015). Characteristics and Attitudes of Entrepreneurs Towards Entrepreneurship. Procedia - Social and Behavioral Sciences, 195, 1087-1096. doi: http://dx.doi.org/10.1016/j.sbspro.2015.06.153

Hamel, G., y Prahalad, C. K. (1994). Competing for the Future Harvard Business School Press. Boston, MA.

Harpa, E., Moca, S., y Rus, D. (2016). A Comparative Study of Rural Entrepreneurship Romania Greece. Procedia Technology, 22, 1100-1105. doi: http://doi.org/10.1016/j.protcy.2016.01.155

Hnátek, M. (2015). Entrepreneurial Thinking as a Key Factor of Family Business Success. Procedia Social and Behavioral Sciences, 181, 342-348. doi: http://dx.doi.org/10.1016/j.sbspro.2015.04.896

Jaramillo, L. (2008). Emprendimiento: Concepto básico en competencias. Colombia, Editorial Universidad del norte Lumen.

Julca Meza, E. (2012). Evaluación de factores básicos de competencia de emprendimiento empresarial en los estudiantes de turismo: El caso de la Universidad San Martín de Porres, Lima (Perú).

Kickul, J., y Gundry, L. (2002). Prospecting for strategic advantage: The proactive entrepreneurial personality and small firm innovation. Journal of Small Business Management, 40(2), 85-97.

Kirzner, I. M. (1997). Entrepreneurial discovery and the competitive market process: An Austrian approach. Journal of economic Literature, 35(1), 60-85.

Koellinger, P., Minniti, M., y Schade, C. (2007). "I think I can, I think I can": Overconfidence and entrepreneurial behavior. Journal of economic psychology, 28(4), 502-527.

Lawson, B., y Samson, D. (2001). Developing innovation capability in organisations: a dynamic capabilities approach. International journal of innovation management, 5(03), 377-400.

Leite, E. (2006). Empreendedorismo, inovação e incubação de empresas: lei de inovação. Recife: Bagaço.

Leite, E., y Gouveia, J. J. B. (2000). O fenômeno do empreendedorismo.

Levy Leboyer, C., y Prieto, J. M. (1997). Gestión de las competencias: Gestión.

Leyva del Toro, C. (2016). Tecnología para la evaluación del desempeño individual alineada al desempeño organizacional. Aplicación en organizaciones turísticas de holguín. (Tesis en opción al título académico de Doctor en Ciencias Técnicas), Universidad de Holguín, Holguín.

Lingling, Y., Xuhui, T., Cunrui, H., y Fei, Z. (2014). Mediating effect of job satisfaction on the relationship between emotional intelligence and perceived general health. Social Behavior Personality: An International Journa, 1,42(7).

Lisetchi, M., y Brancu, L. (2014). The Entrepreneurship Concept as a Subject of Social Innovation. Procedia - Social and Behavioral Sciences, 124, 87-92. doi: http://dx.doi.org/10.1016/j.sbspro.2014.02.463 
Lucas de Souza, E. C. (2005). Empreendedorismo: da gênese à contemporaneidade. Empreendedorismo além do plano de negócios. São Paulo: Atlas.

Lucas Souza, E. C., y Sueiro Lopez, G. J. (2011). Empreendedorismo e Desenvolvimento: Uma Relação em Aberto. RAl Revista de Administração e Inovação, 8(3), 120-140. doi: http://dx.doi.org/10.5773/rai.v8i3.785

Marrero, B. C., y Moré, I. A. (2017). COMPETENCIAS CLAVES PARA LA GESTIÓN DEL CONOCIMIENTO. Universidad $\ \&$ Ciencia, 2, 38-50.

Marrero Fornaris, C. (2002). Tecnología integral para la Gestión de la Formación de recursos humanos en instalaciones hoteleras. (Tesis en opción al grado científico de Doctor en Ciencias Técnicas), Instituto Superior Politécnico "José Antonio Echeverría", Ciudad de La Habana, Cuba.

Maryunani, S. R., y Mirzanti, I. R. (2015). The Development of Entrepreneurship in Creative Industries with Reference to Bandung as a Creative City. Procedia - Social and Behavioral Sciences, 169, 387-394. doi: http://dx.doi.org/10.1016/j.sbspro.2015.01.324

McClelland, D. C. (1973). Testing for competence rather than for" intelligence.". American psychologist, 28(1), 1-1. doi: http://dx.doi.org/10.1037/h0034092.

McClelland, D. C., y Winter, D. G. (1969). Motivating economic achievement.

Miranda, F. J., Chamorro Mera, A., y Rubio, S. (2017). Academic entrepreneurship in Spanish universities: An analysis of the determinants of entrepreneurial intention. European Research on Management and Business Economics, 23(2), 113-122. doi: http://doi.org/10.1016/j.iedeen.2017.01.001

Momete, D. C. (2015). Joining Economic and Engineering Perspectives - A tool for Successful Entrepreneurs. Procedia - Social and Behavioral Sciences, 180, 395-400. doi: http://dx.doi.org/10.1016/j.sbspro.2015.02.135

Morrison, K. (1998). Management theories for educational change: Sage.

North, D. C. (1990). Institutions, institutional change and economic performance: Cambridge university press.

Nová, J. (2015). Developing the Entrepreneurial Competencies of Sport Management Students. Procedia - Social and Behavioral Sciences, 174, 3916-3924. doi: http://dx.doi.org/10.1016/j.sbspro.2015.01.1134

Ortiz, E., y Mariño, M. (2003). Problemas contemporáneos de la didáctica de la educación superior. Cuba, Holguín.

Padilla Martínez, M. P., Quispe Otacoma, A. L., Nogueira Rivera, D., Hernández Nariño, A., y Moreno Gavilanez, K. (2018). El emprendimiento como gestión empresarial para un desarrollo sostenible. Ingeniería Industrial, XXXIV, 196-203.

Panc, I. (2015). Investigating the Entrepreneurial Potential of Students - Design and Preliminary Validity Data of the Assessment Center Method. Procedia - Social and Behavioral Sciences, 203, 393-399. doi: http://dx.doi.org/10.1016/j.sbspro.2015.08.314

Parra Villanueva, L. F., y Fleitas Triana, M. S. (2010). Incubación de proyectos para iniciativas empresariales en la universidad libre de Cali. Ingeniería Industrial, 31.

Pedrosa, M. A. F. (2007). Atitude Empreendedora no Setor Hosteleiro Brasileiro: um estudo com gerentes de pequeños e grandes hotéis do Distrito Federal. (Master en Administración), Universidade de Brasília, Brasília.

Pérez Díaz Pericles, J. M. (2017). La educación emprendedora, una necesidad de nuestros tiempos. Paper presented at the Campus América Universidad de La Laguna.

R. Stoner, C., y Fry, F. L. (1982). The entrepreneurial decision: dissatisfaction or opportunity? Journal of Small Business Management (pre-1986), 20(000002), 39-39. 
Ribeiro Soriano, D. (2001). La innovación en las PYME ante el nuevo entorno económico. Papeles de Economía española(89-90), 286-296.

Ripsas, S. (1998). Towards an interdisciplinary theory of entrepreneurship. Small Business Economics, 10(2), 103-115.

Robles Álvarez, M. A. (2015). Emprendimiento como enfoque de efectividad en la gerencia de los procesos organizativos en las empresas de producción social. (Tesis presentada en opción al grado científico de Doctorado en Ciencias Gerenciales), Universidad Privada Dr. Rafael Belloso Chacín, Maracaibo. Venezuela.

Rodrigues de Siqueira, W., Peghini, P., Dias de Souza, L., y Bentode Oliveira Filho, J. (2014). Atitude empreendedora de proprietários e funcionários intraempreendedores: Um estudo comparativo entre visionários e visionistas. Revista ReGePe, 3(1), 84-104.

Rusque, A. M., Ramírez, C., Torres, G., Guzmán, S., y Castillo, C. (1998). Medición de Capacidad Emprendedora de Estudiantes de Escuelas de Administración de Europa y América Latina (Red Alfa. Comunidad Europea) XII Congreso Latinoamericano Sobre Espíritu Empresarial San José. Costa Rica.

Salas, A. C. (2014). Development of Attitudes towards Entrepreneurship. Procedia - Social and Behavioral Sciences, 139, 189-197. doi: http://dx.doi.org/10.1016/j.sbspro.2014.08.057

Schumpeter, J. A. (1984). The meaning of rationality in the social sciences. Zeitschrift für die gesamte Staatswissenschaft/Journal of Institutional and Theoretical Economics(H. 4), 577-593.

Smallbone, D., y Welter, F. (2001). The distinctiveness of entrepreneurship in transition economies. Small Business Economics, 16(4), 249-262.

Sobel, R. S. (2008). Testing Baumol: Institutional quality and the productivity of entrepreneurship. Journal of Business Venturing, 23(6), 641-655.

Stevenson del Vecchio, M., y Velázquez Zaldívar, R. (2007, 2007). El emprendimiento como eje transversal del currículo del administrador de empresas. Universidad Autónoma del Caribe Barranquilla.

Stewart, W. H., y Roth, P. L. (2007). A meta-analysis of achievement motivation differences between entrepreneurs and managers. Journal of Small Business Management, 45(4), 401421.

Sueiro Lopes, G. J., y Souza, E. C. L. d. (2006). Instrumento de medida da atitude empreendedora-IMAE: construção e validação de uma escala. Encontro da Associação Nacional de PósGraduação e Pesquisa e Administração, 30.

Teixeira, R. M., Ducci, N. P. C., Sarrassini, N. d. S., Munhê, V. P. C., y Ducci, L. Z. (2011). Empreendedorismo jovem e a influência da família: a história de vida de uma empreendedora de sucesso. REGE - Revista de Gestão, 18(1), 3-18. doi: http://dx.doi.org/10.5700/rege411

Timmons, J. A., Spinelli, S., y Tan, Y. (1994). New venture creation: Entrepreneurship for the 21st century (Vol. 4): Irwin Burr Ridge, IL.

Turan, M., y Kara, A. (2007). An exploratory study of characteristics and attributes of Turkish entrepreneurs: A cross-country comparison to Irish entrepreneurs. Journal of International Entrepreneurship, 5(1-2), 25-46.

Uslu, T. (2015). Innovation Culture and Strategic Human Resource Management in Public and Private Sector within the Framework of Employee Ownership. Procedia - Social and Behavioral Sciences, 195, 1463-1470. doi: http://dx.doi.org/10.1016/j.sbspro.2015.06.445

Vainrub, R. (2009). Una guía para emprendedores: convertir sueños en realidades: Prentice Hall. Valcarce, J. n., y Sequera, Á. M. n. (2005). Aprender a emprender. Abogados, 123(234), 653-654. 
Valliere, D. (2015). An Effectuation Measure of Entrepreneurial Intent. Procedia - Social and Behavioral Sciences, 169, 131-142. doi: http://dx.doi.org/10.1016/j.sbspro.2015.01.294

Van Praag, C. M., y Cramer, J. S. (2001). The roots of entrepreneurship and labour demand: Individual ability and low risk aversion. Economica, 68(269), 45-62.

Veciana Vergés, J. M. a. (1996). Generación y desarrollo de nuevos proyectos innovadores." Venture management" o" corporate entrepreneurship". Economía industrial(310), 79-90.

Vereshchagina, G., y Hopenhayn, H. A. (2009). Risk taking by entrepreneurs. The American Economic Review, 99(5), 1808-1830.

Wankel, C., y F. Stoner, J. A. (2009). Management education for global sustainability: IAP.

Weber, E. U. (2003). Origins and functions of perceptions of risk. Paper presented at the $\mathrm{NCl}$ Workshop on 'Conceptualizing and Measuring Risk Perceptions', Washington, DC, February.

Wilken, P. H. (1979). Entrepreneurship: A comparative and historical study: Norwood, NJ: Ablex Publishing Corporation.

Yıldırım, N., Çakır, Ö., y Aşkun, O. B. (2016). Ready to Dare? A Case Study on the Entrepreneurial Intentions of Business and Engineering Students in Turkey. Procedia - Social and Behavioral Sciences, 229, 277-288. doi: http://dx.doi.org/10.1016/j.sbspro.2016.07.138

Yurtkoru, E. S., Kuşcu, Z. K., y Doğanay, A. (2014). Exploring the Antecedents of Entrepreneurial Intention on Turkish University Students. Procedia - Social and Behavioral Sciences, 150, 841850. doi: http://dx.doi.org/10.1016/j.sbspro.2014.09.093

Zaman, G. (2015). Cultural Heritage Entrepreneurship (CHE) - Challenges and Difficulties. Procedia - Social and Behavioral Sciences, 188, 3-15. doi: http://dx.doi.org/10.1016/j.sbspro.2015.03.333

Zaman, G., Vasile, V., y Cristea, A. (2012). Oustanding Aspects of Sustainable Development and Competitiveness Challenges for Entrepreneurship in Romania. Procedia Economics and Finance, 3, 12-17. doi: http://dx.doi.org/10.1016/S2212-5671(12)00114-1

Zayas Agüero, P. (2002). ¿Cómo seleccionar al personal por competencias? Editorial Academia. Ciudad Habana, Cuba.

Zimmerer, T., y Scarborough, N. M. (1996). Entrepreneurship and new venture formation: Prentice Hall. 